\title{
An Overview of Self-piercing Riveting Process with Focus on Joint Failures, Corrosion Issues and Optimisation Techniques
}

Hua Qian Ang ${ }^{*}$ D

\begin{abstract}
Self-piercing riveting (SPR) is a cold forming technique used to fasten together two or more sheets of materials with a rivet without the need to predrill a hole. The application of SPR in the automotive sector has become increasingly popular mainly due to the growing use of lightweight materials in transportation applications. However, SPR joining of these advanced light materials remains a challenge as these materials often lack a good combination of high strength and ductility to resist the large plastic deformation induced by the SPR process. In this paper, SPR joints of advanced materials and their corresponding failure mechanisms are discussed, aiming to provide the foundation for future improvement of SPR joint quality. This paper is divided into three major sections: 1) joint failures focusing on joint defects originated from the SPR process and joint failure modes under different mechanical loading conditions, 2) joint corrosion issues, and 3) joint optimisation via process parameters and advanced techniques.
\end{abstract}

Keywords: Self-piercing riveting, Mechanical joining, Joint defects, Failure mechanisms, Corrosion, Joint optimisation

\section{Introduction}

Self-piercing riveting (SPR) process was originated around half a century ago [1] and it was mainly used by appliance and packaging industry. It was first developed as an alternative to the resistance spot welding (RSW) process for joining of aluminium. RSW is not suitable for aluminium joints because aluminium has high thermal conductivity and low melting point; the electrical conductivity of aluminium also makes the electrical current requirement for RSW process high. Aluminium can also react and contaminate the copper spot welding tip, reducing the tool life [2]. Although RSW of aluminium is still possible using specially designed electrodes [3], SPR is still the most preferred option for joining aluminium components.

SPR only rose to prominence during the last decades when it was adopted by Audi to join the structural panels in the all-aluminium Audi A8 [4]. Since then, a significant

*Correspondence: huaqian.ang@rmit.edu.au

School of Engineering, RMIT University, Bundoora, Victoria 3083, Australia progression has been the application of SPR technique to both space frame (Audi A2) [5] and monocoque designs (Jaguar) [6,7].

The increasing interest in the use of lightweight and high strength ratio materials in vehicle fabrication to reduce the weight of vehicle is due to the urgent need to reduce fuel consumption and greenhouse gas emissions, and hence, is partly the cause of renewed interest in SPR technology. This is because hybrid use of different lightweight alloys, such as magnesium with aluminium alloys [8] or aluminium with advanced high strength steel [9] can sometimes be difficult or impossible to weld due to differences in thermal, physical and chemical properties.

Compared with other joining techniques such as RSW, friction stir spot welding (FSSW) and its variant "linear" friction stir welding (FSW) [10], clinching and adhesive bonding, SPR has proven to be an effective process to join dissimilar materials, from aluminium with composite [11] to aluminium with advanced high strength steel [12]. RSW, on the other hand, is typically used in welding steels than welding other light alloys [13-15]. Friction 
stir is a more time consuming process $(2-5 \mathrm{~s})[9,16]$ than RSW ( $<1 \mathrm{~s})$ [17] and SPR (1-2 s) [18], and clinching is normally used to join non-load bearing structures, such as trunk lid and engine hoods due to its low joint strength [9]. Whilst adhesive bonding can join almost all types of materials, even when one of the joining materials is nonmetallic, e.g., polymers and composites [19], careful surface preparation, such as surface cleaning and surface treatment need to be carried out prior to bonding. Some adhesives require heat curing after bonding to reach the required strength, and this may take up to weeks to complete. Heat curing may also affect the properties of the joined materials [20] and induce problems, such as debonding, distortion or even fracture of adhesive due to the differences in thermal expansion coefficients between adhesive and adherends [21, 22]. To date, SPR is still the first choice in automotive applications when considering the intensive use of aluminium. Other advantages and disadvantages of SPR process are reported [23, 24].

With the growing use of SPR, comes the need to understand the failure mechanisms of SPR joints, however, literature survey on joint performance is lacking. Most studies on SPR concentrated on comparing the mechanical properties of joints manufactured by SPR and RSW techniques. For example, Mori et al. [25] observed the static strengths of SPR to be about 1.5 and 1.2 times higher than that of the RSW under tension shearing and cross tension tests, respectively in their aluminium alloy sheets. Two types of failure mechanisms were observed: rivet pull-out in SPR and sheet fracture in RSW. Sun et al. [26] reported the fatigue strength of SPR to be more than $100 \%$ higher than the fatigue strength of RSW for fatigue lives ranging from $10^{5}$ to $10^{6}$ cycles under lap shear and cross tension tests. A range of failure modes were also observed under SPR and RSW. Mizukoshi and Okada [27] reported a fatigue ratio of 0.4 for their SPR joints; this is two times higher than RSW joints. The superior fatigue behaviour of SPR was attributed to the fact that SPRs do not have the single-point crack tip (or notch tip) stress concentration effects as those in RSW [28].

However, there are some inconsistencies reported to date. Several authors [29-32] have shown that the static strength of SPR joints is some degree lower than RSW joints. Booth et al. [29] reported 25\% lower static failure loads in SPR joints as compared to RSW joints in joining steel sheets, under both lap shear and T-peel testing. Razmjoo and Westgate [30] observed lower static strength in SPR joints than RSW joints in both steel to steel and aluminium to aluminium joints, with up to $30 \%$ reduction in strength in the aluminium specimens using SPR. It seems that there is no definitive answer as to which process would produce a higher-strength joint. The performance of a SPR joint depends on a variety of factors, such as processing parameters, loading conditions, properties of the materials being joined and the rivet. Any potential joint defects introduced during riveting may also affect the behaviour of the joint, resulting in different joint strengths reported in literature.

There is a review paper [23] on SPR process, but the content is general, briefly reviewing all aspects from mechanical properties to finite element analysis and cost analysis of SPR joints. The current review is more focused, discussing the different types of failure mechanisms of SPR joints and their corrosion issues as well as summarising the potential joining optimisation techniques to improve different rivet joints. Structural SPR joints play a significant role in load transfer within an assembly. Understanding SPR joint failures and corrosion issues is necessary to continuously make improvements to achieve better load carrying capacity of riveted structures.

\section{SPR Process}

\subsection{SPR Joint Formation}

SPR is a cold forming process that is used to fasten together two or more sheets of materials by driving a rivet through the upper sheet and upsetting the rivet in the lower sheet without penetration into the lower one. Joining is achieved by rivet locking into the lower sheet. Since the process relies on a mechanical interlock rather than fusion, it can be used on any materials and combinations of materials. Examples are combinations of steel to aluminium alloys [33] and titanium to copper and aluminium alloys [34], and even aluminium alloys to some low-ductility metals such as ultra-high strength steel [35] and magnesium alloys [8].

The SPR process is illustrated in Figure 1. This technique is divided into the following four distinct stages [36-39]:

1. Clamping and/or Bending: The sheets to be joined are first clamped together between a blank holder and a die. In some cases, pre-clamping is not involved, and sheets bend as rivet being pushed by a punch perpendicularly to the sheet surface. The punch is driven down using either a hydraulic or electrical system. In this phase, the rivet clamps the sheets.

2. Piercing: The rivet shank acts as a shearing punch that pierces into the entire thickness of the upper sheet. The lower sheet is pierced only partially until the rivet reacts against the influence of the die.

3. Flaring: The rivet flares into the die and forms a mechanical interlock between the sheets. The lower sheet undergoes plastic deformation and flows into the die cavity due to the large applied force. There- 


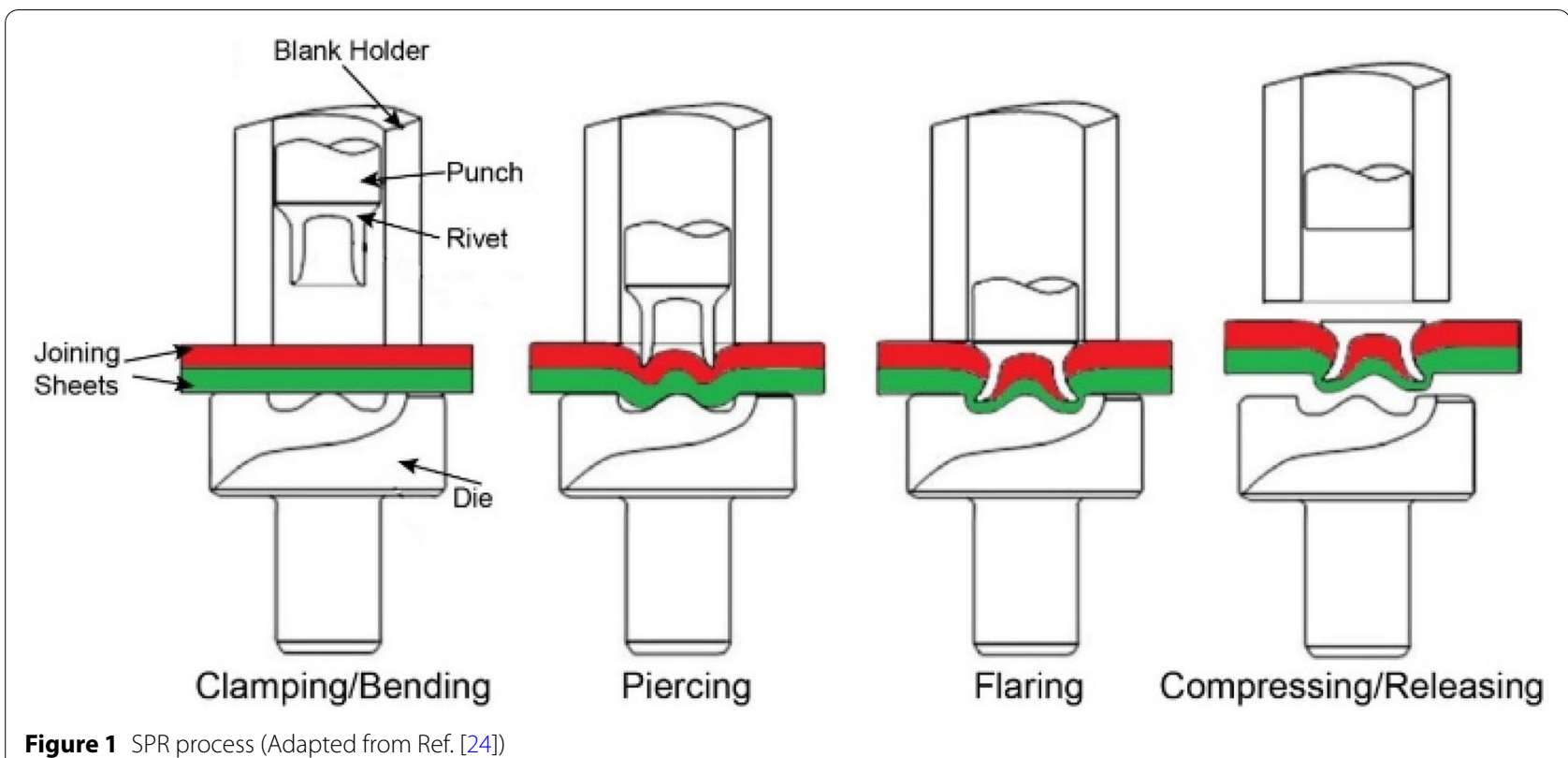

fore, the lower sheet conforms to the shape of the cavity, forming a buttonhole at the bottom.

4. Compressing and Releasing: The punch continues the stroke, pushing the rivet inside the sheet metals further. The punch stops when it reaches a predetermined force or stroke and then slowly releases.

\subsection{SPR Joint Quality Monitoring}

In order to ensure strong and reliable SPR joints, a range of quality monitoring methods have been developed to give an overall picture of the joint quality. These SPR quality monitoring processes can be classified into destructive and non-destructive testing methods. Destructive methods, such as lap shear, cross tension and coach peel tests (described in Section 3.2) can be carried out to answer the question concerning real joint performance during loading, but they are more time-consuming and costly as compared to non-destructive methods. Currently, the most prominent non-destructive techniques for SPR are setting force observation [38], visual joint assessment [40, 41], and ultrasonic testing [42].

Setting force-punch displacement has been established as one of the most important parameters during SPR joint assessment. It can be a useful indicator of process performance and joint quality. A typical four-stage setting force-displacement curve for the SPR process, shown in Figure 2, can also be found in various studies [43-45].

Stage I involves bending of the sheets before the rivet starts to penetrate the upper sheet. The upper sheet plastically deforms and no failure occurs as long as the stress generated is below the tensile strength of the sheet material. In this region, the force increases slowly with increasing punch displacement. The length of this stage decreases with increasing rivet hardness and sheet stiffness as a result of early penetration of rivet into the upper sheet, initiating Stage II [38]. During Stage II, rivet has now pierced into the upper sheet and the force now reaches the tensile strength of the upper sheet material and remains constant as the rivet penetrates through the lower sheet. Lower sheet material also starts to flow into the die cavity. The length of this stage mainly depends on the upper sheet thickness. In Stage III, the force starts to rise with a higher gradient as the rivet leg is further spread, allowing more materials to flow inside the die cavity. Greater die volume and higher rivet hardness will increase the die filling time, lengthening this stage. In Stage IV, rivet head is set to the correct position and force continues to rise as the rivet continues to compress the sheets, closing up the gap between the upper and lower sheets. This forms an interlock. Increasing rivet hardness without compromising the rivet ductility will ensure more flaring and a better interlocked joint, extending this stage.

The force-displacement curve is often compared with a reference curve [38]. If the process curve fits within a pre-defined tolerance of the reference curve, the joint is passed; otherwise the joint may be flagged for attention or the SPR process may even be halted.

Visual evaluation of the SPR joint is worthwhile because appearance can give a good validation of joint 


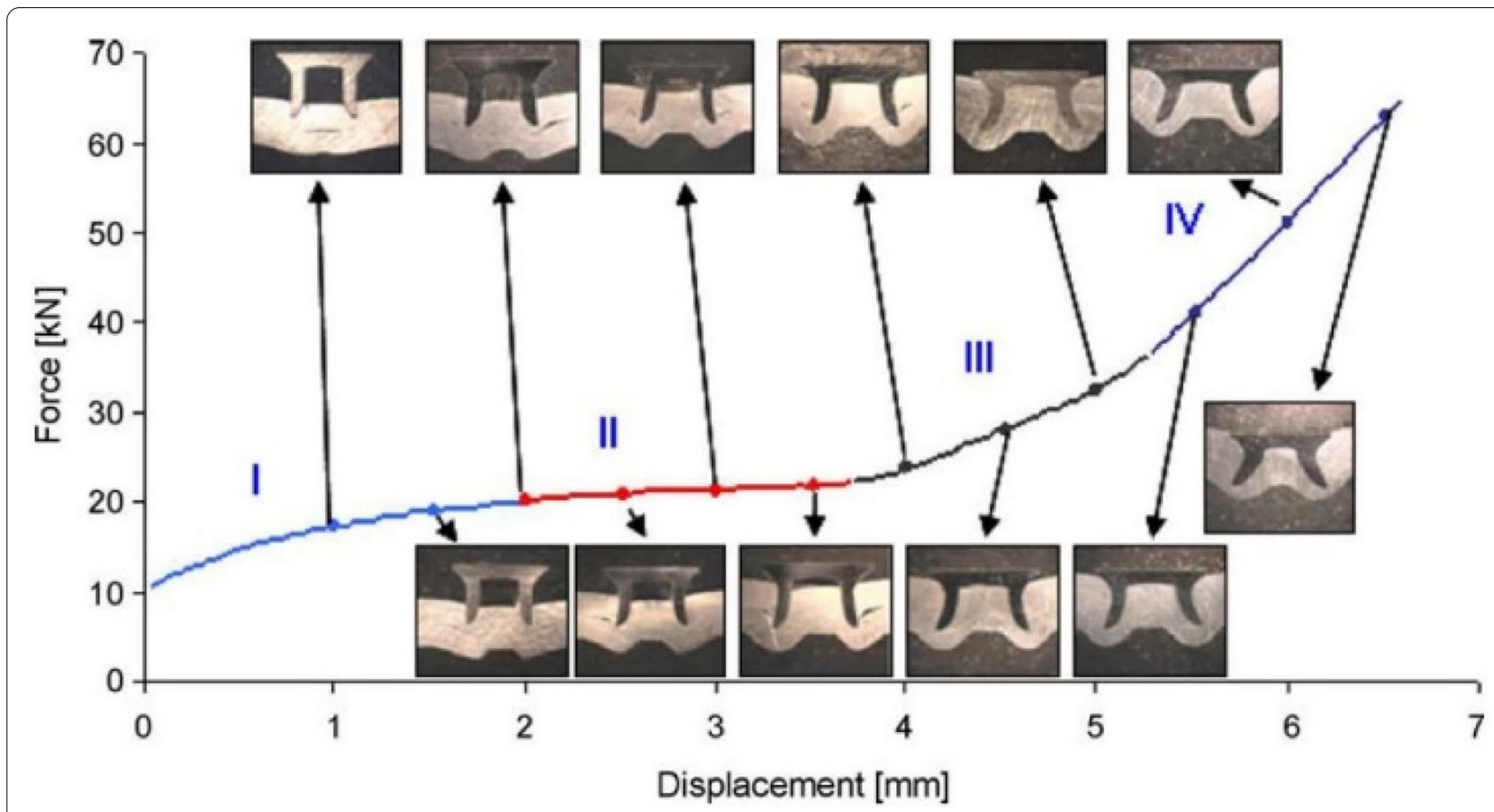

Figure 2 A force-displacement curve of a SPR process [43]

quality. A more detailed visual inspection can include examining a cross-sectioned joint to allow assessment of the joint's interior features [40]. To avoid material wastage, X-ray Computed Tomography, Ultrasonic C-Scan and a computer vision with laser sensors [46] can be introduced into the SPR process for this purpose. The important geometrical quality features of SPR joints are the rivet head height, remaining bottom thickness, undercut, horizontal and vertical interlock distances in the lower sheet [24, 47-50], as illustrated in Figure 3.

On the top side, a good joint will have the rivet head in firm contact with the upper sheet, for example, there should be no gap between the rivet head and upper sheet as well as no cracks in the rivet head or in the surrounding materials. The rivet head height is important to control the aesthetic appearance and the amount of interlocking in the joint without damaging the upper sheet. Bottom thickness represents the distance from the tip of the rivet leg to the outer surface of the lower sheet. It is also important to ensure some amount of bottom thickness so that the rivet leg does not cut through the lower sheet or be noticeable. For some applications, the remaining bottom thickness might not be crucial, but it is important for components subjected to fatigue loading or corrosive environments. Undercut is the radial distance between outer surface of rivet shank tip and the point where the rivet pierces through the upper sheet. Undercut determines the amount of interlock between the rivet and the sheets [50]. For industry applications, the remaining bottom thickness and undercut must be greater than $0.2 \mathrm{~mm}$ [49]. The interlock distance is another important joint quality to ensure good amount of rivet flaring and no gap between the upper and lower sheets around the rivet leg. There is no single minimum value for the interlock distance, as it is highly dependent on the joint stacking sequence, sheet material properties and thickness. For example, the minimum required interlock distance for aluminium joints is $0.4 \mathrm{~mm}$ while for steel is $0.2 \mathrm{~mm}$ based on industry standard practice [51]. On the die side, there should be a symmetrical button of the correct diameter and shape (determined by the die).

Ultrasonic testing is another approach to detect abnormal joints in comparison with sound joints. These studies $[42,52]$ have proposed a method of using narrowband ultrasonic spectroscopy to inspect SPR joint by sending an ultrasonic continuous wave using a differential piezoelectric transducer operating at a predetermined frequency. Detailed information about the principle of narrowband ultrasonic spectroscopy can be found in the literature [53]. According to these studies [42, 52], the transducer is provided with a waveguide that is acoustically coupled to the rivet head. The rivet quality can be evaluated by monitoring the variations in the electrical impedance of the transducer. The difference between the impedance corresponding to the inspected rivet and the predetermined scatter of values corresponding to 


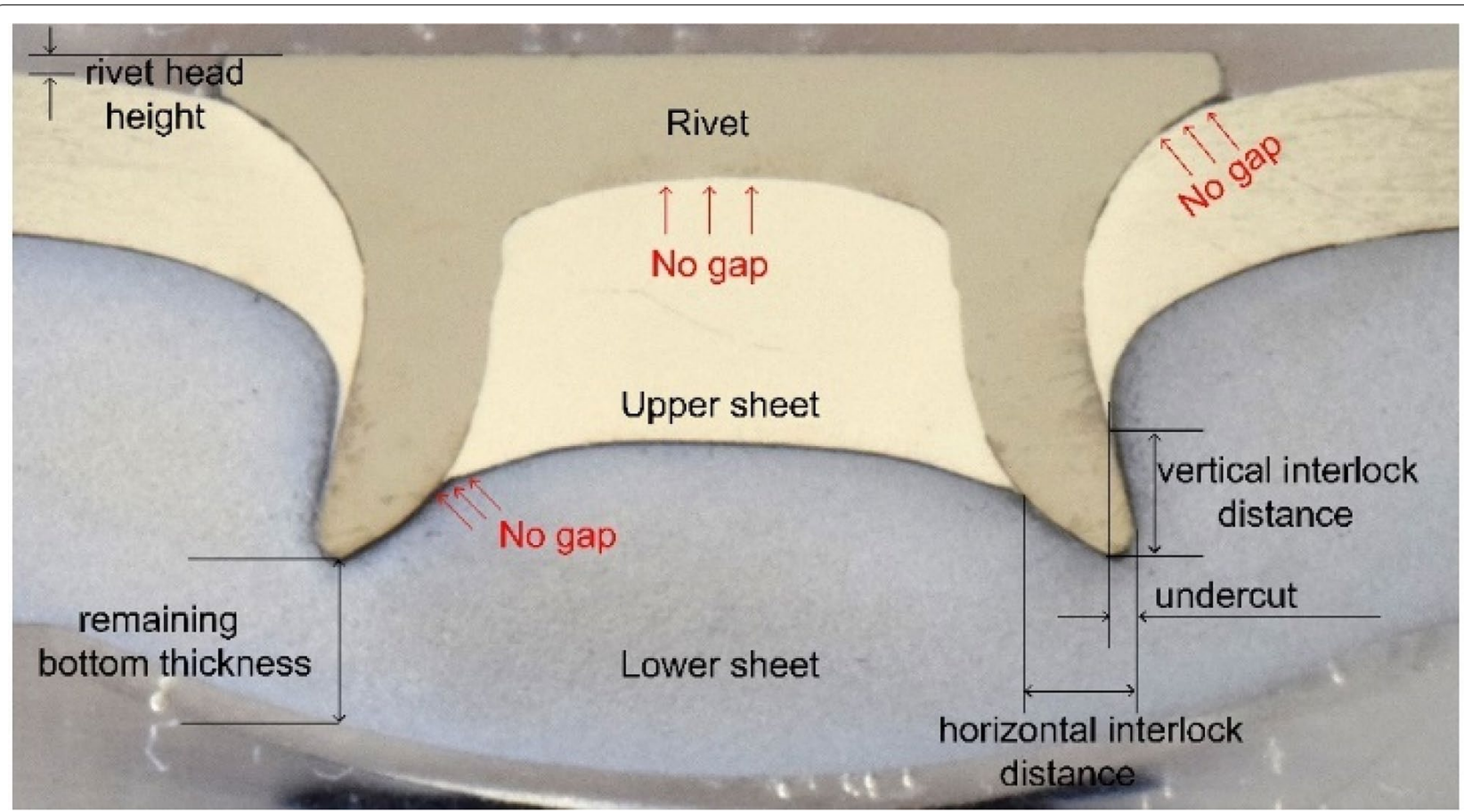

Figure 3 The geometrical quality features of a SPR joint

sound rivets is then monitored. This technique was able to detect sound and bad joints for some of the aluminium joints with two and three layers [42]. However, the sensitivity of this technique is not good for joints involving very thin aluminium sheets and steel panels; further improvement is necessary.

\section{Joint Failures}

\subsection{Defects in SPR Joints}

With SPR increasingly used in vehicle assemblies, it is important to understand the potential defects that may occur during the riveting process before joining condition can be optimised. Incompatible geometry and material selection, inadequate material properties of joining sheets and rivet and improper processing condition can all lead to joint imperfections which will in turn affect the integrity of the joint. This section discusses the different types of defects occurred in the joining sheets and rivet.

Joining sheets. The sheets to be joined could be damaged through penetration of rivet through the lower sheet, necking of the lower sheet and separation of the sheets $[9,54]$ as shown in Figure 4 . In the penetration through the lower sheet, the leg of the rivet passes through the bottom surface of the lower sheet, and a site for corrosion is formed. Corrosion of SPR joints

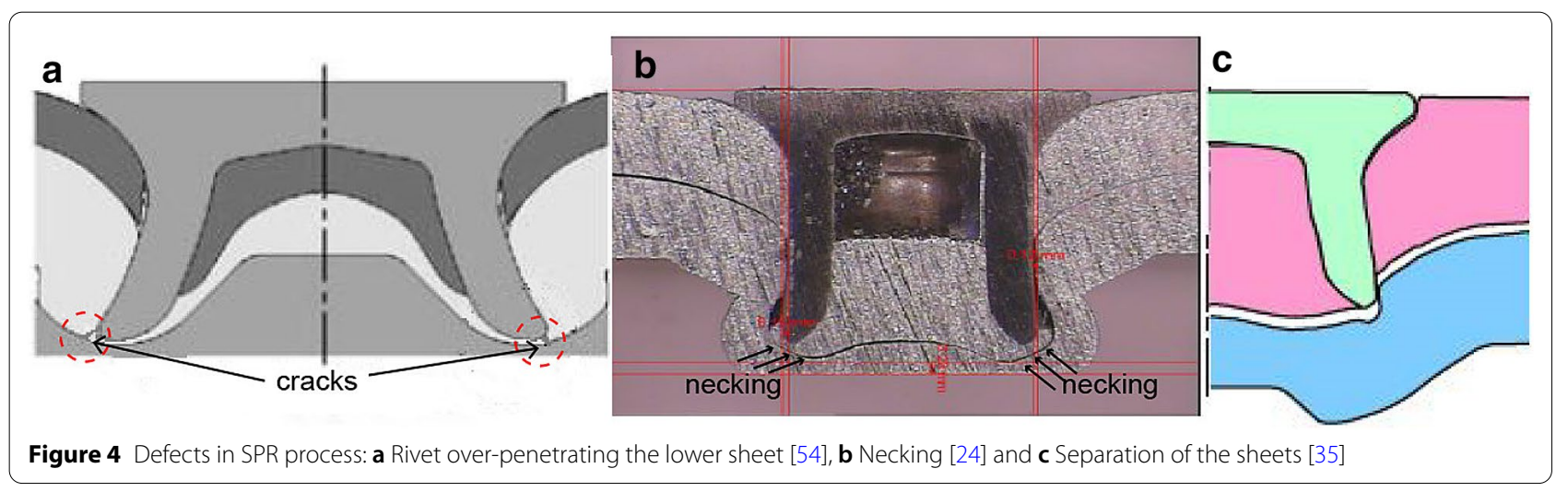


is discussed in Section 4. Penetration of rivet through the lower sheet can cause the lower sheet to fracture as observed by Mori et al. [35] when joining aluminium alloy as the upper sheet and ultra-high strength steel as the lower sheet. Similar defect also reported in the joining of upper aluminium sheet with lower glass fibre or carbon fibre reinforced polymer composite sheet, namely GFRP and CFRP, respectively [55]. The low ductility of steel and composite sheets makes large plastic deformation difficult and prevents the rivet leg to spread uniformly in the lower sheet, leading to rivet over-penetration. Some suggestions are to use higher-ductility material as the lower sheet, for example, placing steel sheet on top and aluminium sheet below [35], or use a shorter rivet to avoid full penetration through the lower sheet [55].

The necking of the lower sheet is a localised thinning phenomenon, which can also result in penetration defect and weak interlocking between the sheets. Necking of the lower sheet is observed when the lower sheet is made of high strength steel; hard lower sheet makes flaring of the rivet skirt difficult, leading to necking phenomenon [56]. Necking also occurs when the lower sheet to be joined is too thin relative to the upper sheet. A thin lower sheet cannot accommodate the large plastic deformation required when flowing into the die cavity. Die cavity may have different sizes; a deeper die cavity will obviously introduce larger plastic deformation in the lower sheet, increasing the likelihood of necking at the joint button [24]. In addition to material properties, sheet thickness and die size, friction between the upper and lower sheet interfaces is another factor to consider. A large friction between the upper and lower sheets may result in uneven deformation, leading to localised stress concentration and necking in the lower sheet [57].

Separation of upper and lower sheets, on the other hand, is caused by insufficient penetration or spreading of the rivet leg to join the sheets. As a consequence, the riveted sheets are easily separated. This usually occurs when the sheets to be joined are stronger and harder than the rivet [9].

In addition to the aforementioned SPR joint defects, sheet cracking may occur when piercing through materials with low room-temperature ductility such as magnesium alloys [8, 58-61], aluminium die castings [62], and fibre-reinforced composites [11, 55, 63-65]. Figure 5(a) shows the cross-section of aluminium (upper sheet) to die-cast magnesium alloy AE44 (lower sheet) SPR joint assembly. No defect is observed in the upper sheet of aluminium but cracks are observed in the lower sheet of magnesium alloy after riveting which may lead to subsequent failure under loading. Sheet inner fracture and cracks initiated at the tip of the rivet (as indicated by the arrows in Figure 5(a)) are associated with the poor room-temperature formability and ductility of magnesium alloys. These properties are inherently related to the hexagonal closed-packed crystal structure. In another riveted joint of aluminium alloy 6063 with die-cast magnesium alloy AM50, similar cracking was constantly observed in the magnesium alloy sheet, despite the different rivet and die configurations used [61]. The possibility of riveting other higher-ductility wrought magnesium alloy, e.g., AZ31 has also been investigated, and undesirable joints with microcracks are observed [60]. An additional pre-heating step prior to SPR is required to obtain a better joint quality when riveting magnesium alloys [60]. This advanced technique is discussed in more detail in Section 5.

Another challenging material to rivet is aluminium diecasting AlSi9Mn. In the joining of aluminium 6016 and die-cast AlSi9Mn, several cracks formed in the lower AlSi9Mn sheet and propagated to the joint button [62]. Crack in the lower sheet does not only compromise fatigue resistance, it can also trap water or moisture and lead to corrosion.

The feasibility of using SPR to join metals and composites has also been investigated [11, 55, 63, 64, 66-68]. Two common defects observed in riveted composite sheets are fibre damage and delamination. Zhang and Yang [55] studied the riveting of composites with aluminium alloy, and they observed fibre delamination and folding in the GFRP composite sheet. In the same study, they also observed additional cracking in the CFRP composite sheet as CFRP has even lower ductility than GFRP. An example of fibre breakage and delamination of CFRP sheet in a composite-aluminium joint is shown in Figure 5(b), reproduced from [68]. These defects may propagate and cause premature failure when the joint is loaded under fatigue cyclic stresses.

Rivet. In addition to joint defects from sheets, there is a possibility of rivet damage during SPR process. Rivet damage or failure may include rivet leg compression, rivet leg bending and rivet leg fracture as shown in Figure 6 . These rivet defects normally occur when piercing through thick and strong material sheets [35], or when the rivet used has low ductility and strength, for example aluminium rivet $[69,70]$. If the rivet used is too soft for the joining sheets, the rivet leg will have difficulty driving through the hard upper sheet and flaring into the hard lower sheet. This will, in turn, lead to a series of problems, such as weak interlocking between the rivet and sheets, affecting the joint strength or rupturing of lower sheet which may introduce a site for corrosion [71].

Rivet fracture can occur in a number of ways, such as cracking in the joining direction, compression cracks and internal cracks as reported by Eckstein et al. [72] Rivet may crack in the joining direction when the 

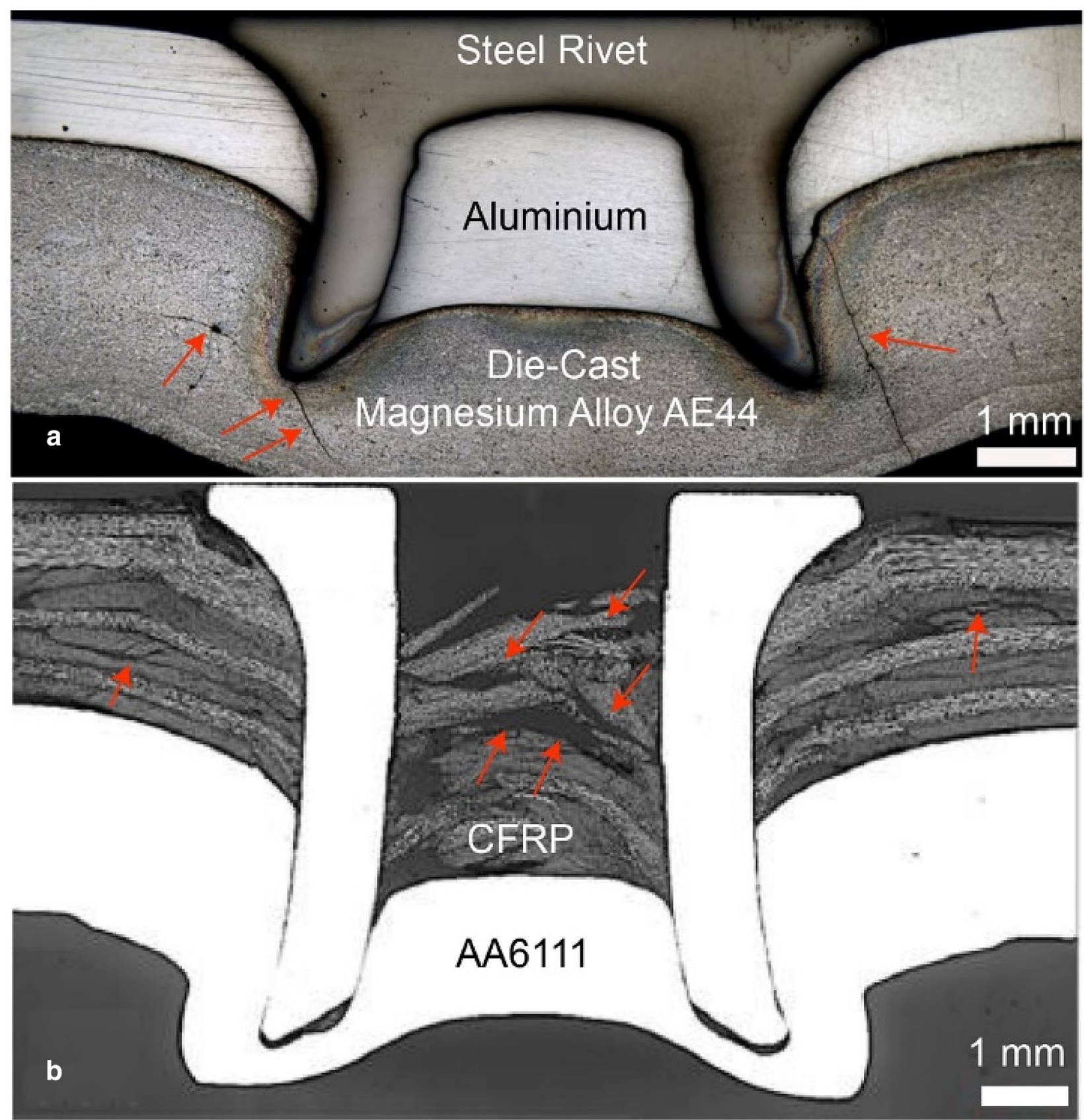

Figure 5 Cross-section view of SPR joint assembly: a upper sheet of aluminium and lower sheet of die-cast magnesium alloy AE44 and $\mathbf{b}$ upper sheet of carbon fibre reinforced composite (CFRP) and lower sheet of aluminium alloy AA6111 ((b) is reproduced from Ref. [68]). Arrows in a indicate sheet cracking and in $\mathbf{b}$ fibre breakage and delamination

bore of the self-piercing rivet is filled, especially when joining soft materials, forcing the rivet to spread substantially. This sort of crack displays a ductile dimple fracture. Rivet cracks in the joining direction due to high circumferential stresses when rivet reaches its maximum forming capacity. Compression cracks may be seen when the rivet leg is compressed and fractured along the compression folds. This usually happens when the joining sheets are harder than the rivet or when the friction between the interfaces of the joining sheets is high. Internal cracks, whereas, occur when there is an excessive load in the rivet shaft. Removal of punch in the last step of SPR process can result in a brief increase of tensile stresses in the rivet shaft area, 


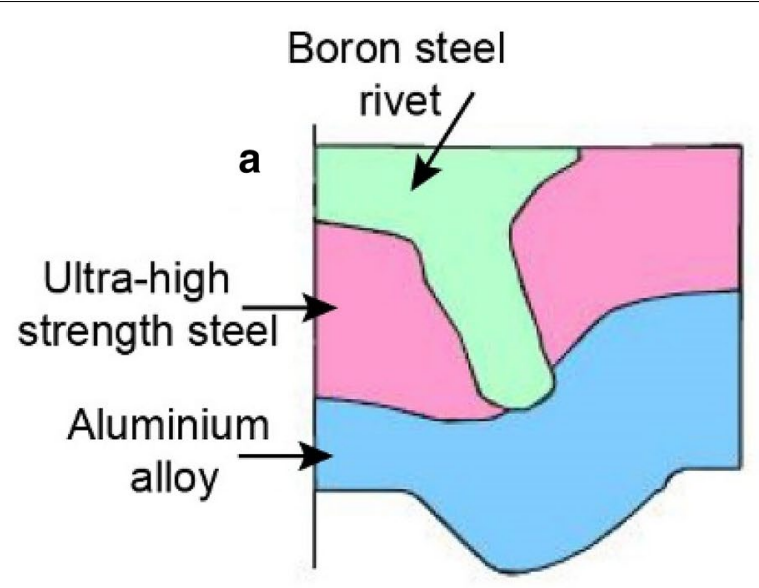

b
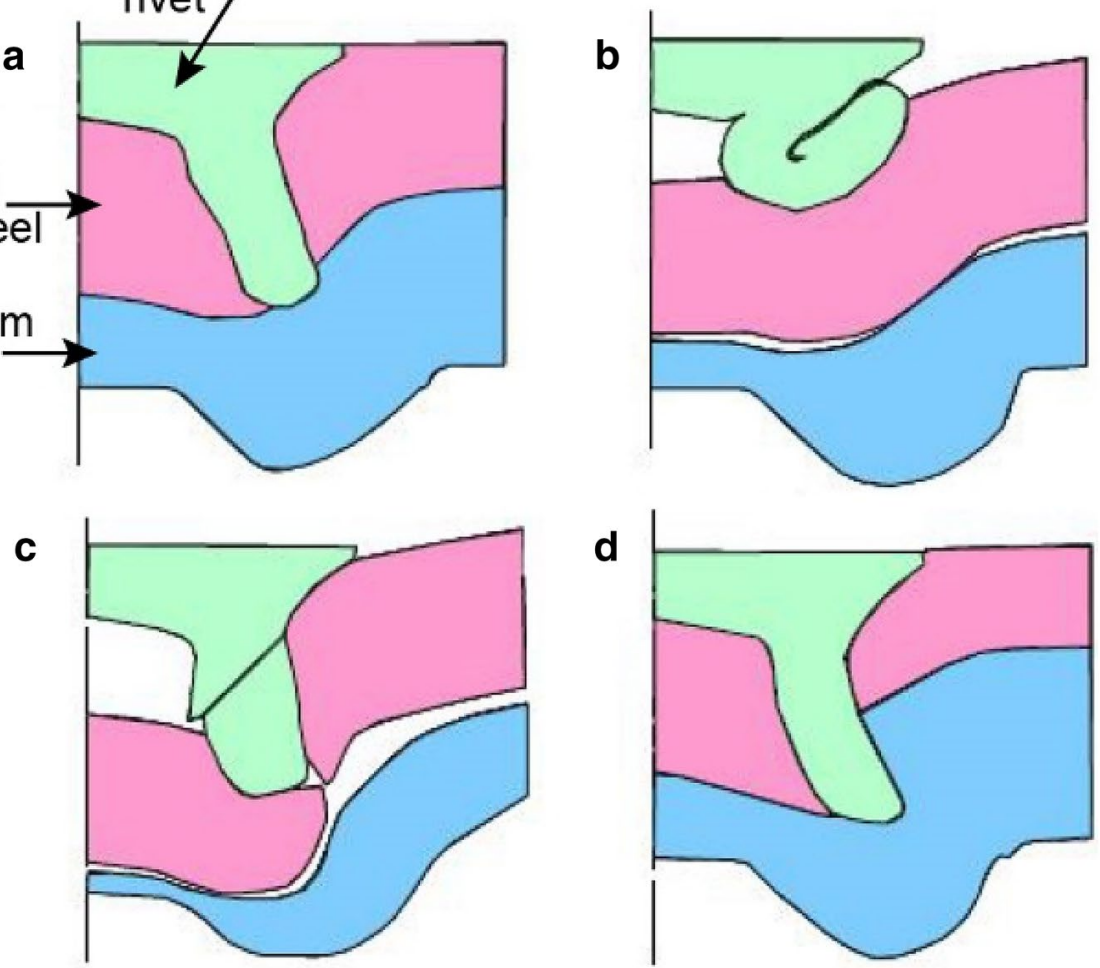

Figure 6 Rivet damage: a leg compression, $\mathbf{b}$ leg bending, and $\mathbf{c}$ leg fracture. A defect-free joint is shown in $\mathbf{d}$ for comparison [35]

a
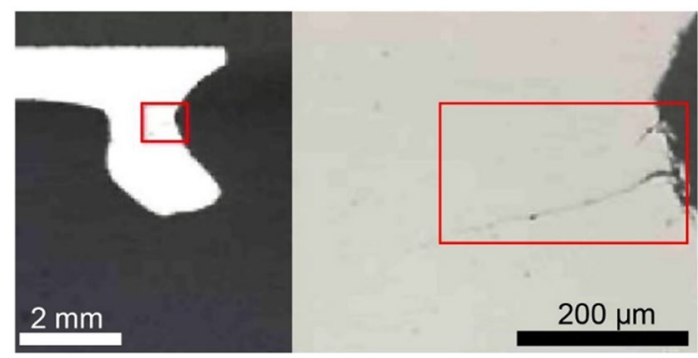

b

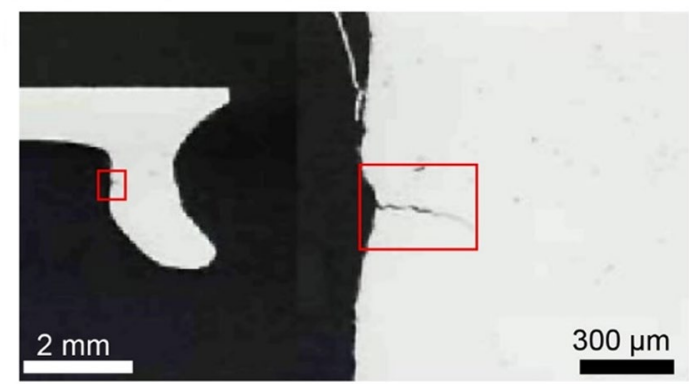

Figure 7 Types of rivet fractures: $\mathbf{a}$ compression cracks and $\mathbf{b}$ internal cracks [72] resulting in internal cracks. Compression cracks and internal cracks are shown in Figure 7.

In short, joinability is greatly influenced by the stacking sequence, sheet material properties and thickness. Where dissimilar materials are being joined, it is recommended to apply rivet in the direction of brittle to ductile or thin to thick material for a better joint quality. For instance, magnesium die casting is placed on top of aluminium extrusion to improve joint strength [61]. However, there is no guarantee that this suggestion will provide a defectfree joint. As seen in a steel-aluminium joint, placing high strength steel on top may cause rivet leg compression due to similar strength between the sheet and rivet while placing high strength steel below may result in sheet penetration and necking [71]. Care should be taken if the sheets and rivet have similar material properties. As for sheet thickness, SPR can fasten a total joint stack thickness of $1.6 \mathrm{~mm}$ to $10 \mathrm{~mm}$, depending on the joining materials. Ideally, the upper sheet should be at least 0.5 mm thick and the lower sheet should be at least $1 \mathrm{~mm}$ thick [73]. 


\subsection{Failure Modes under Mechanical Loading}

Actual rivet joints in a vehicle can experience combined and complex loading conditions; therefore, any SPR strength characterisation must also consider different loading conditions. This section discusses the different types of mechanical tests on SPR joints and their commonly observed failure modes under different types of loadings. Fretting wear under fatigue loading is also discussed.

Lap shear, cross tension and coach peel tests are commonly used to characterise the joint strength and energy absorption levels of SPR joints under static and fatigue loading conditions. Figure 8 illustrates the specimen configurations and loading conditions of these tests, taken from [74]. Under lap shear testing, the sheets are pulled apart and against the rivet. The joint resistance to failure

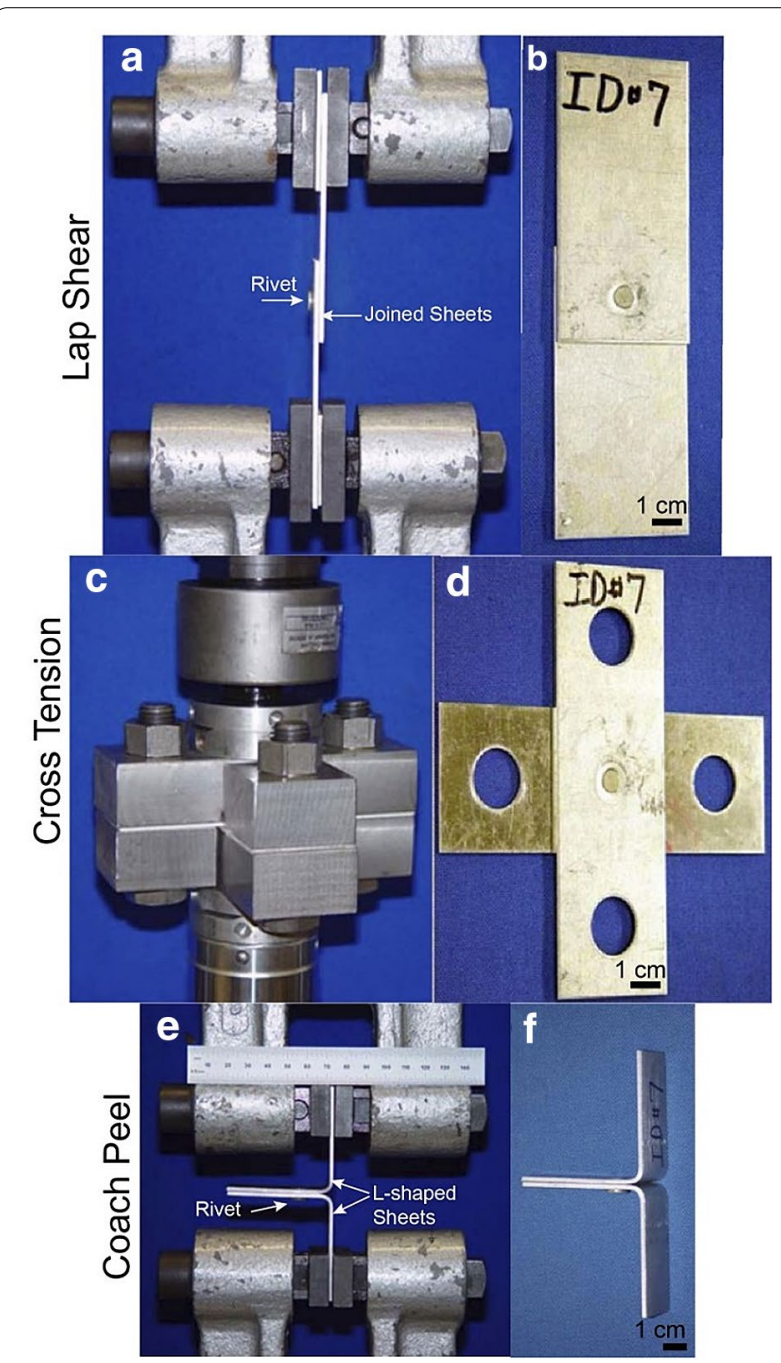

Figure 8 Loading conditions $\mathbf{a}, \mathbf{c}, \mathbf{e}$ and specimen configurations $\mathbf{b}$, $\mathbf{d}$ and $\mathbf{f}$ of lap shear, cross tension and coach peel testing, respectively for SPR strength characterisation [74] is offered by both the friction resistance (contact pressure between the sheets) and rivet shear resistance [75]. Under this type of loading condition, sheets must have high stiffness and ductility to delay the activation of damage mechanisms of the joint, while rivet must have high shear strength to withstand the tangential shearing force. Under cross tension loading, the upper sheet is pulled against the rivet head, and the lower sheet is pulled against the flared portion of the rivet skirt [76]. The yield strength of the sheets is more important than tensile strength since material necking and hardening are less significant. During coach peel testing, the joint is subjected to pure shear condition. The peeling specimen is composed of two L-shaped sheets. The small flanges are joined with one rivet while the long flanges are clamped into the testing machine. During the pull-out, rivet will tilt and rotate in its attempt to slide out from the sheets, generating yield and fracture in the sheets [77]. Hence, sheets with high yield strength and toughness are required to delay the onset of failure.

Mechanical failure modes of SPR joint observed under static and fatigue testings are rivet head pull-out as shown in Figure 9(a) (rivet head is pulled out from the upper sheet) [76], rivet tail pull-out in Figure 9(b) (rivet tail is pulled out of the lower sheet) [78], sheet bending (Figure 9(c)) and cracking (Figure 9(d)) [78-82].

Rivet head or tail pull-out. For joining two sheets made of the same material, the failure mode is dependent on the sheet thickness. According to Li et al. [24], if the upper sheet is thicker than the lower sheet, joint is likely to fail by rivet tail pull-out (Figure 9(b)), whilst if the upper sheet is thinner, joint is failed by tearing of upper sheet, leading to rivet head pull-out (Figure 9(a)). For joining of dissimilar materials, the failure mode does not only depend on sheet thickness, it also depends on material strength [83]. For a joint stack of AISI 1008 low carbon steel (1.4 $\mathrm{mm}$ upper sheet) and aluminium alloy 5182 ( $2 \mathrm{~mm}$ lower sheet), the joint was failed by rivet tail pull-out from the lower aluminium sheet under lap shear loading even though the lower aluminium sheet was thicker [26]. This suggests that the failure mode is also determined by the resistance of the sheet materials to bearing and to rivet being pulled out.

Sheet bending. Refer to Figure 9(c), sheet bending is particularly observed in thin sheets (thickness of less than or equal to $1 \mathrm{~mm}$ ) on the rivet head side, leading to either tearing or shearing of the upper sheet. Sheet bending may also induce sheet rotation [84], allowing the rivet head to pull through the upper sheet more easily. This type of failure is even more visible if the upper sheet is made of low-ductility materials, such as magnesium and aluminium alloys. 


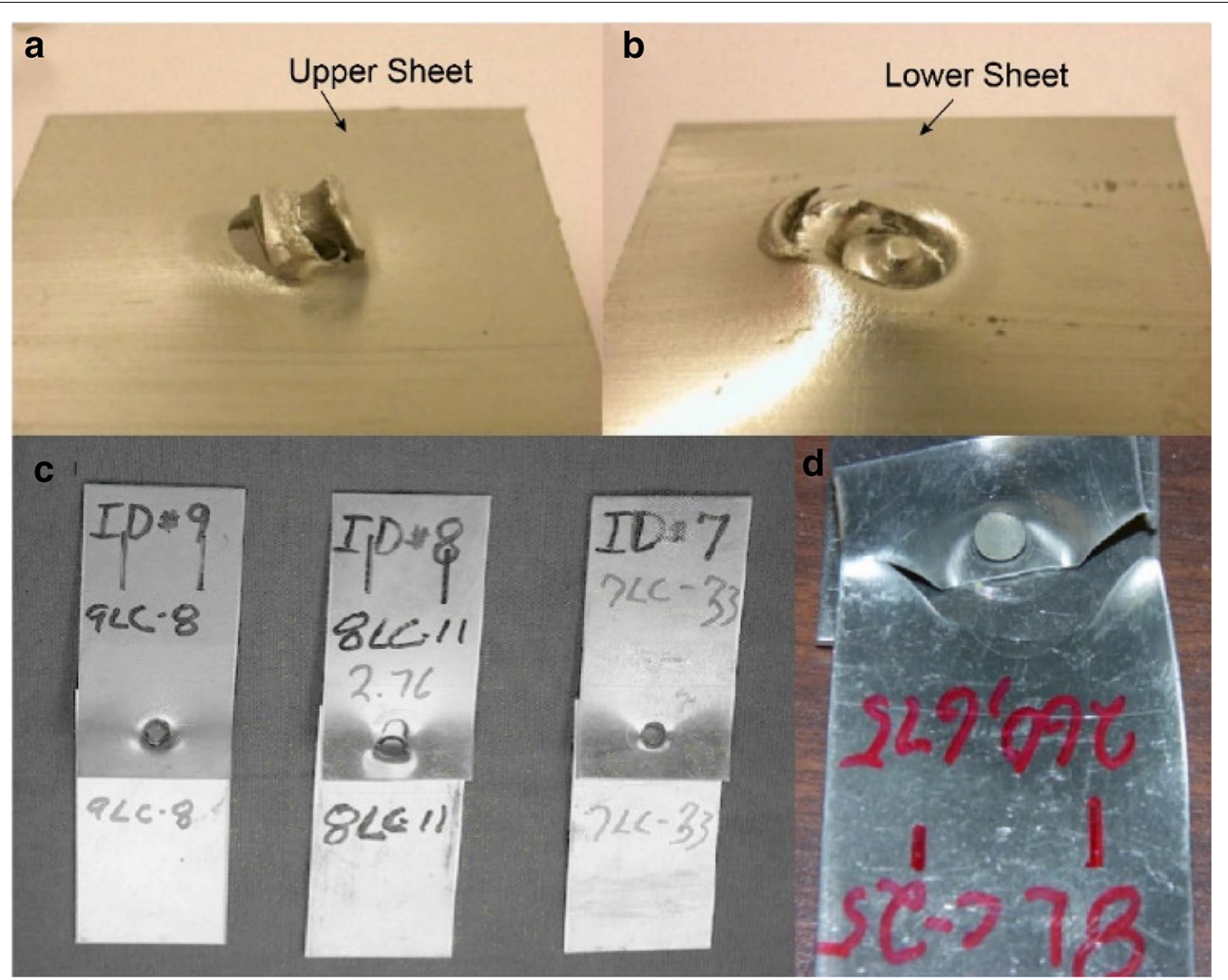

Figure 9 Failure modes of SPR joint under mechanical testing: a rivet head pull-out and $\mathbf{b}$ rivet tail pull-out [78], $\mathbf{c}$ sheet bending [58] and $\mathbf{d}$ sheet cracking: head side eyebrow crack [26]

Sheet cracking. The joined sheets may also crack in a few ways depending on the loading condition. Under quasi-static loading condition, some transverse cracks were initiated around the rivet head, at the circumference of the hole in the upper sheet while a circumferential crack was initiated at the tip of the rivet leg and propagated to the lower sheet as observed by $\mathrm{Su}$ et al. [79] under lap shear configuration. Without sufficient support from the upper sheet, the rivet was rotated clockwise, and the sheets were bent severely, leading to rivet pull-out. In the same study under cyclic loading, a different failure mode was observed whereby cracks were emanated from the curved interfacial surface of the upper sheet and propagated into the upper sheet, leading to upper sheet separation. This type of failure is manifest as eyebrow cracking shown in Figure 9(d). Eyebrow cracking is one of the most commonly seen failure modes under fatigue testing [26, 79, 81]. Other types of cracks, such as tail side and head side sheet cracking might also occur depending on the stress concentration mechanisms that resulted from different loading conditions [85].

In the case of hybrid metal-composite joints, failures under mechanical testing are more likely to occur in the brittle composite sheet. One of the most commonly seen failures is bearing failure as shown in Figure 10(a), which is caused by compression and subsequent folding of the composite material at the back of the rivet $[63,64]$. It usually occurs when the width of the composite sheet is too small compared to the rivet diameter [11]. The initiation of such failure mechanism also depends on the fibres' orientation of the laminate material [64]. Another type of mechanical failure mode observed in aluminiumcomposite joints is face cracks as shown in Figure 10(b). Face cracks first initiate on the CFRP sheet around the rivet, which then propagate through the width of the sheet under loading [66, 67]. This type of fracture is induced by a non-uniform stress state close to the rivet section (high stress concentration due to rivet hole).

Fretting wear. When a SPR joint experiences a load, part of the load will be transferred by friction between the contacting surfaces. The presence of such frictional force is essential for the proper function of the joint; without this frictional force, the joint will be weaker. However, at the same time, presence of friction at the contacting surfaces often leads to fretting fatigue. Fretting is initiated upon the application of a cyclic load. 

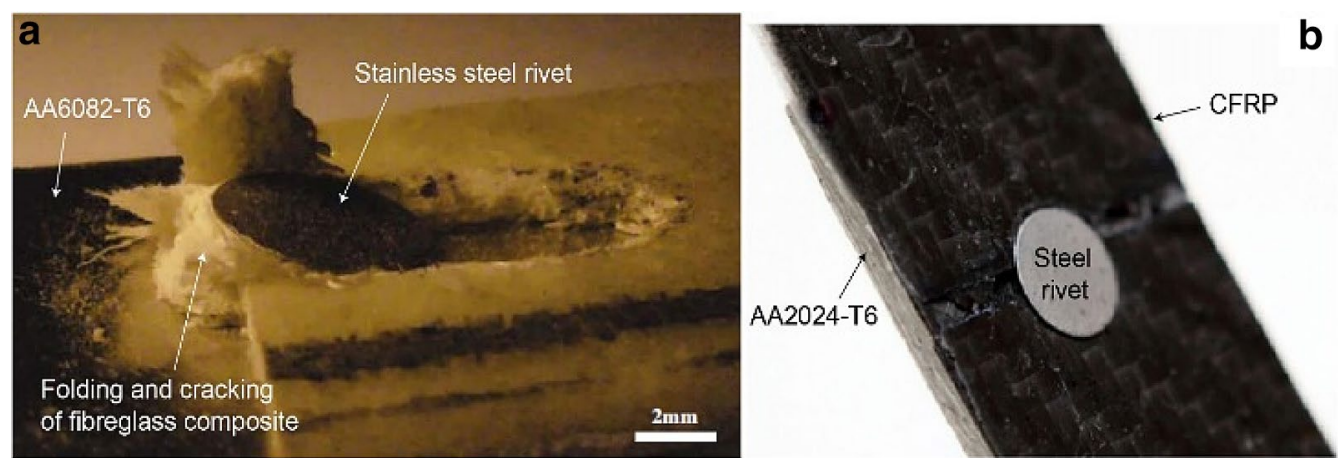

b

Figure 10 Failure modes observed in aluminium-composite joints under tensile loading: a bearing failure [63] and $\mathbf{b}$ face cracks [67]

During the initial stages of fretting, fretting scars may not be visible to the naked eye. It is noted that fretting wear is initially patchy and the scars are not deep [86]. If an alloy is coated with a solid lubricant, early fretting will involve wear of the solid lubricant layer. As the number of loading cycle increases, black scars that are typical of fretting wear gradually appear. Black debris resulted from fretting may accumulate around the rivet leg, increasing the roughness of the contact interface, thereby further increasing the friction and resulting in more debris [87]. As fretting damage progresses, stress concentration can build up at these areas leading to the nucleation of a fatigue crack, and then fracture. Hence, the presence of fretting can significantly degrade the fatigue life [88-91].

Fretting may develop at different locations during cyclic loading as observed by Chen et al. [86] in an aluminium alloy SPR joint. Based on their observation, fretting occurred at two locations, $\mathrm{A}$ and $\mathrm{B}$ as marked in Figure 11(a). Location $A$ is the interface between the sheets while location $B$ is the interface between the rivet and lower sheet. In location $\mathrm{A}$, as fatigue cycle increased while applied load remained constant at 4.5 $\mathrm{kN}$, fretting area also increased, producing more fretting debris (compare Figures 11(b) with (c)). It is clear that the fretting areas are covered with oxidised wear debris coloured black and the boundary between the fretting and the non-fretting zones can be clearly distinguished. In location B, marked in Figure 11(a), circumferential fretting scar and some scattered fretting scars were observed on the rivet surface where the rivet was interlocked with the lower sheet as shown in Figure 11(d). The width of the circumferential fretting scar was reported to be approximately $0.5-0.8 \mathrm{~mm}$. Fretting wear can eventually lead to surface work hardening, crack initiation and propagation during fatigue testing. It is also interesting to point out that no fretting was reported at location $\mathrm{C}$ which is the interface between the rivet head and upper sheet (marked as $\mathrm{C}$ in Figure 11(a)) in this study [86].

In similar AA5754 SPR joints, Iyer et al. [93] observed fatigue crack initiation which was accompanied by fretting wear at: (1) the sheet to sheet and (2) the rivet head to upper sheet interfaces, corresponding to locations A and $\mathrm{C}$ in Figure 11(a), respectively. The severity of fretting wear was found to increase with sheet thickness. This contradicted the findings from Zhao et al. [94] who observed that fretting wear between the sheets decreased with increasing sheet thickness. They attributed the lower degree of fretting to the reduced relative movement between thicker sheets [94]. It should be pointed out that Iyer et al. [93] employed aluminium alloy 5754-O while Zhao et al. [94] used aluminium alloy AA5052 in their studies.

Apart from sheet thickness, the sheet/sheet interfacial condition also plays an important role in minimising fretting wear. Han et al. [92] studied the fretting behaviour of an aluminium joint under different interfacial conditions: as-rolled uncoated aluminium alloy sheets, wax-based lubricant-coated aluminium alloy sheets and samples of uncoated sheets with a PTFE insert to prevent direct contact between the riveted sheets. Their results showed that presence of a wax-based solid surface lubricant could delay the onset of fretting wear at the alloy surface, increasing the fatigue life of the sheets. Although the application of a PTFE insert at the interface between the sheets managed to lower the frictional force and reduce fretting damage, there was a decrease in the fatigue life of the SPR joint with PTFE insert. The reduction of frictional force at the interface led to a significant increase in the bearing load on the rivet, reducing the fatigue life.

Overall, SPR joints can fail in a number of ways under mechanical loading, such as rivet pull-out, bending, tearing or shearing of sheets, and fretting. Rivet pull-out can occur from the upper sheet (rivet 


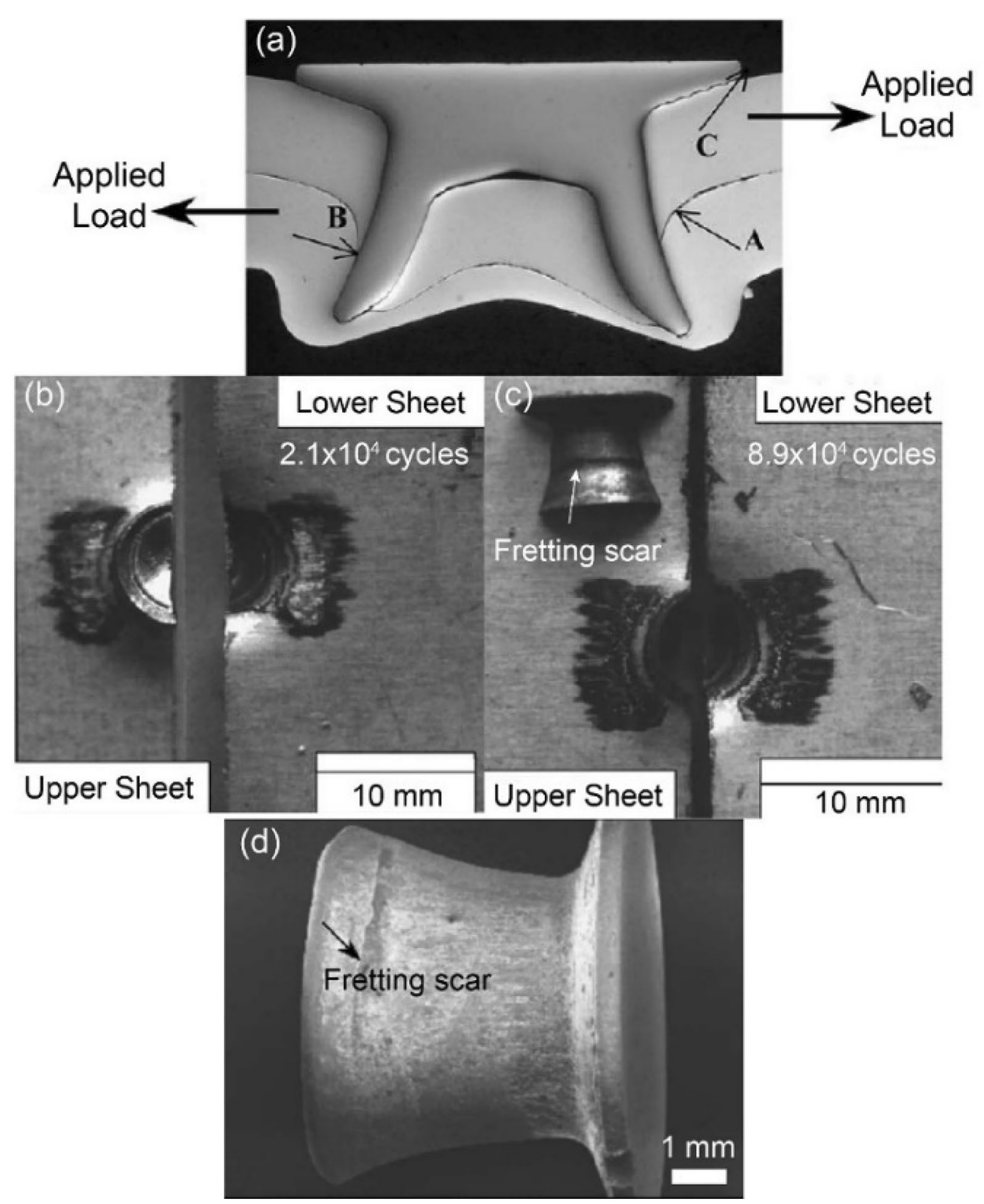

Figure 11 a Fretting locations A, B and C in an aluminium alloy AA5754 joint [92], b, c fretting wear at location A after $2.1 \times 10^{4}$ cycles and $8.9 \times 10^{4}$ cycles, respectively and $\mathbf{d}$ fretting scar at location B [86]

head pull-out) or from the lower sheet (rivet tail pullout); the type of rivet pull-out is dependent on sheet thickness and sheet material properties against bearing and tension. Sheet bending occurs when the upper sheet thickness is too small to resist the loading force, leading to tearing or shearing of the sheet near the rivet head. Fretting damage is an important failure mode observed under fatigue loading, which can lead to surface work hardening, crack initiation and propagation, and eventually reducing the fatigue life of an SPR joint. The different types of joint defects and failure modes under mechanical loading described in this Section are summarised in Figure 12.

\section{Corrosion Issues of SPR Joints}

SPR is an effective process to join multiple dissimilar materials, however, an issue with SPR joint is the risk of corrosion in critical environmental conditions. The 


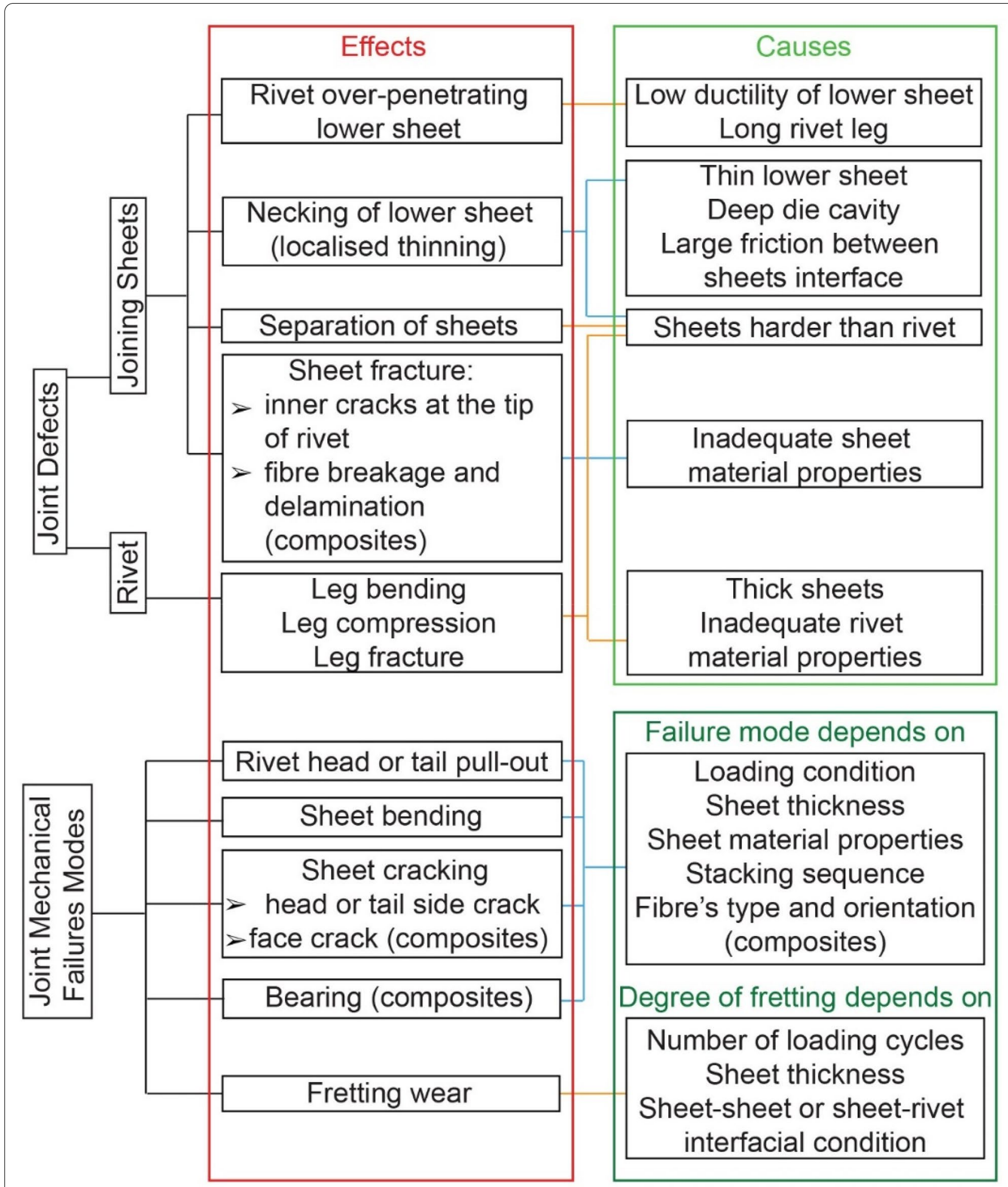

Figure 12 Types of SPR Joint failures

most common forms of corrosion in SPR joints are galvanic corrosion, crevice corrosion, and filiform corrosion (for magnesium sheets) as discussed in this section.
Unlike joint defects which occur during the riveting process, corrosion happens over time. Corrosion degradation phenomena could influence significantly both 
the performance and failure mechanisms of SPR joints [95].

Galvanic corrosion occurs when dissimilar, conductive materials are joined, and the ingress of water forms an electrolytic cell. A potential difference usually exists when two dissimilar metals are in contact. The metal with more electronegative potential will act as anode, while the other acts as cathode. The material is uniformly corroded as the anodic and cathodic regions moves and reverses from time to time [96]. Joining steel with aluminium is a common cause of galvanic corrosion due to the great discrepancy in electric potential [97]. To reduce the risk of galvanic corrosion, it is recommended to use rivet manufactured from the same material as the sheets being joined [23], for example joining aluminium alloy sheets using aluminium rivets [69].

However, if the sheets and rivet used are of dissimilar materials, then coating is a desirable method to minimise galvanic corrosion $[48,98]$. Coating is applied on the material with the most electropositive potential (cathode), such as steel in a steel-aluminium joint. The amount of corrosion was observed to reduce significantly by using a cadmium plating or a polyester coating on a steel rivet for joining aluminium sheets [99]. Other types of coating include electrophoretic coating (e-coat), and electroplating with zinc and a combination of tin-zinc. E-coat and zinc plating are normally applied on steel assemblies [48], while tin-zinc coating is normally used for aluminium car bodies. Tin-zinc coatings have been used for corrosion protection of self-piercing rivets in the Jaguar $\mathrm{XJ}$ as well as the Audi TT. The use of e-coat in conjunction with tinzinc plating has proven to be very effective in improving the corrosion resistance of car bodies. The presence of a coating not only provides a barrier action to galvanic corrosion phenomena, but, at the same time, reduces crevice corrosion due to the sealing of crevice area. Besides, coating the steel rivet with a protective layer can help to lubricate the rivet and reduce the friction between the rivet and joining sheets during riveting [24]. Apart from coating, paint and adhesive can also minimise galvanic corrosion [100].

Crevice corrosion, also known as differential aeration corrosion, is a severe form of local corrosion that takes place inside a metal-metal crevice and a metalnon-metal crevice [101]. As the name suggests, crevice corrosion arises due to surface irregularities or crevices formed in SPR joints. Inside a crevice, the oxygen and $\mathrm{PH}$ levels decrease while the chloride ion concentration increases. Such change in the chemical environment causes the formation of anodic region at the metal surface inside the crevice. The adjacent outer metal surface plays the role of a cathode [102]. Once crevice corrosion begins, it progresses very rapidly [99].
This corrosion mechanism is typically observed at the interfaces of the sheets that are joined and at the gap between the rivet and the pierced sheets (for example, at areas below the rivet head). Maximising the interlocking between the rivet and the sheets [75] through SPR process optimisation (discussed in Section 5) can minimise crevice corrosion.

Some researchers reported that crevice corrosion could not occur in magnesium alloys because magnesium corrosion is insensitive to oxygen concentration differences [103, 104]. A form of corrosion occurs at the crevice of magnesium alloys is called filiform corrosion, and it is not a true crevice corrosion [105]. Filiform corrosion is caused by trapped moisture in the crevices between the joined magnesium sheets which, being unable to evaporate, promotes corrosion over time. To minimise filiform corrosion, a protective coating with low water vapour transmission rates can be applied on the surface of magnesium sheets before riveting [105]. A proper inspection should also be carried out after coating to ensure absence of coating defects, such as hole, which can trap moisture and dirt.

Once corrosion initiates, it progressively deteriorates the SPR joint. One example is sheet thinning due to corrosion degradation [75, 95, 106]. Figure 13 shows sheet thinning in a steel-aluminium joint at different ageing time. In the beginning ( 0 week), there is no corrosion build-up in the joint. In the first week, oxide layers begin to form in the rivet interstices and in between the sheets (location A in Figure 13). At this stage, the degree of corrosion is not significant enough to rupture the joint. In weeks 3 and 7, corrosion product increases progressively within the joint (compare locations $\mathrm{B}$, and $C$ in Figure 13), thinning the lower aluminium sheet, and eventually leading to joint failure at locations D and

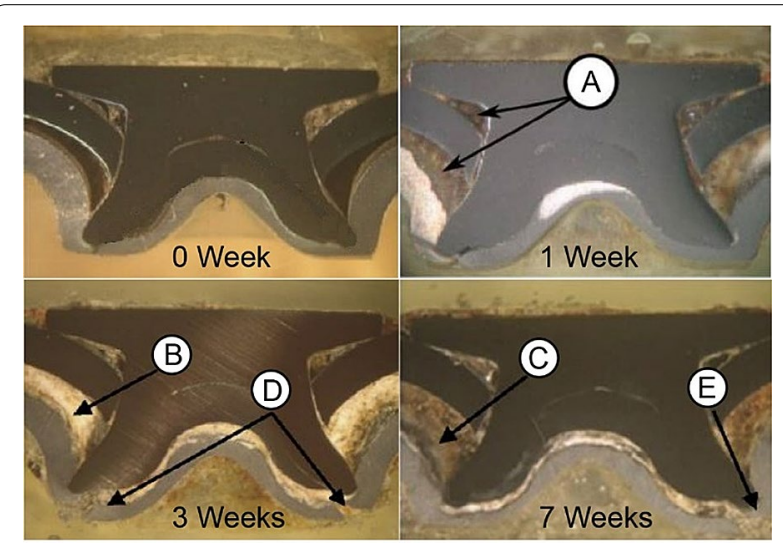

Figure 13 Cross-section of a carbon steel A570 (upper sheet) and aluminium alloy 6082 (lower sheet) riveted joint in salt spray environment at different ageing time [75] 
E in Figure 13. Sheet thinning was observed to decrease the joint load carrying capacity and changed the failure mode from bearing to rivet tail pull-out, and finally fracture by shear-out [106]. To account for sheet thinning effect, it is recommended to use a thicker sheet for better mechanical stability $[75,95]$.

Another effect of corrosion worth mentioning is stress corrosion cracking. As the rivet pierces into the upper sheet, sheet material flows outwards, creating internal tensile stresses within the material [107]. The combined influence of these residual stresses induced by riveting and corrosion effect could facilitate the activation and propagation of local cracks, known as stress corrosion cracking. Stress corrosion cracking can further weaken the SPR joint [108]. The 7xxx series aluminium alloys are particularly susceptible to stress corrosion cracking [107], and heat treatment can be performed on the joint immediately after riveting to minimise stress corrosion cracking [65].

Although some researchers believe that the build-up of corrosion product can tighten the SPR joints and provide necessary friction at the interface between the sheets, and consequently increasing the joint strength [100], in the long term, corrosion will damage the sheet materials and adversely affect the durability and strengths of SPR joints $[106,108]$.

\section{SPR Joint Optimisation}

To minimise SPR joint failures and to obtain a good riveted joint, several process parameter optimisation approaches and advanced SPR techniques have been created and employed. Process parameter optimisation involves optimisation of riveting parameters, such as rivet and die while advanced SPR techniques often require significant changes to the conventional SPR process. Therefore, process parameter optimisation is generally preferred over advanced SPR techniques. This is because the change of manufacturing process by an advanced SPR technique may be prohibited due to the practical issues of the assembly plant. This section first discusses the process parameter optimisation approaches, followed by advanced SPR techniques.

\subsection{Process Parameter Optimisation}

SPR process parameter optimisation includes optimisation of rivet geometry, riveting direction, riveting force, rivet setting velocity, die, sheet thickness and materials properties of sheets and rivet. In terms of rivet geometry, longer rivets clinch more material. An increase in strength and energy absorption was observed in joints with long rivet under static loading condition [58]. Long rivet appears to contribute to the performance of the joint, but additional flaring is necessary to avoid the rivet from perforating the lower sheet [109]. Rivet leg bending and compression may also occur if the rivet leg is too long. Most commonly used rivet is semi-tubular, and rivet leg length can directly affect the volume of the sheet material filling into the hollow cavity of the rivet [50]. For instance, a long rivet leg may lead the sheet material to fill the rivet cavity inadequately, leading to a gap inside the joint whilst a short rivet leg may cause the sheet material to fill the rivet cavity in advance, making the rivet unable to continue piercing into the sheets. Typically, the rivet leg length is about $70 \%-80 \%$ of the total rivet length [110] and the total rivet length (including rivet head) is approximately equal to the combined thickness of the sheets to be joined, plus $75 \%$ of the rivet shank diameter.

Apart from rivet length, rivet blade angle also has an impact in the SPR joint quality as it can influence the maximum blanking force on the upper sheet [50]. Rivet blade angle must be large enough for the rivet to upset in the sheets, but not too large as excessive blade angle makes the rivet leg more difficult to pierce into the sheets. For composite-aluminium joints, Figure 14(a) shows that blade angle of $30^{\circ}$ provides the largest expansion of rivet leg, and consequently, better interlock with the sheets. For steel-aluminium joints, rivets with blade angle of $40^{\circ}$ was found to be the most suitable [50].

For rivet piercing direction, it is preferable to pierce from brittle or thinner material into ductile or thicker material $[33,58]$. Lower sheet materials will undergo large plastic deformation when deforming into the die cavity, and therefore must have sufficient ductility; otherwise severe cracks will be generated at the joint button. This was seen in magnesium-aluminium joints, where magnesium die casting cracked when placed below aluminium, despite the different rivet and die configurations used in the study [61]. However, cracks were not observed when magnesium die casting was placed on top of aluminium [61]. A ductile lower sheet also allows wider spread of rivet leg for good interlocking [54], and this is advantageous to the static and fatigue strengths of the joint [26]. In a composite-metal structure, composite sheet is always recommended to be placed on top and metal sheet below for a better joint quality $[11,63]$. However, care should also be taken if the upper sheet material is too hard in comparison with the rivet material itself; rivet shank cracking may occur.

Riveting force is another important factor to consider. Mucha [111] showed that increasing the riveting force from $14 \mathrm{kN}$ to $32 \mathrm{kN}$ significantly improved the strength of steel joints by $36 \%$. A larger riveting force should be applied for joining higher-strength sheets. Similarly, in other studies on composite-aluminium joints [63, 64], it was observed that brittle fibreglass composite could be effectively join with aluminium and the mechanical 


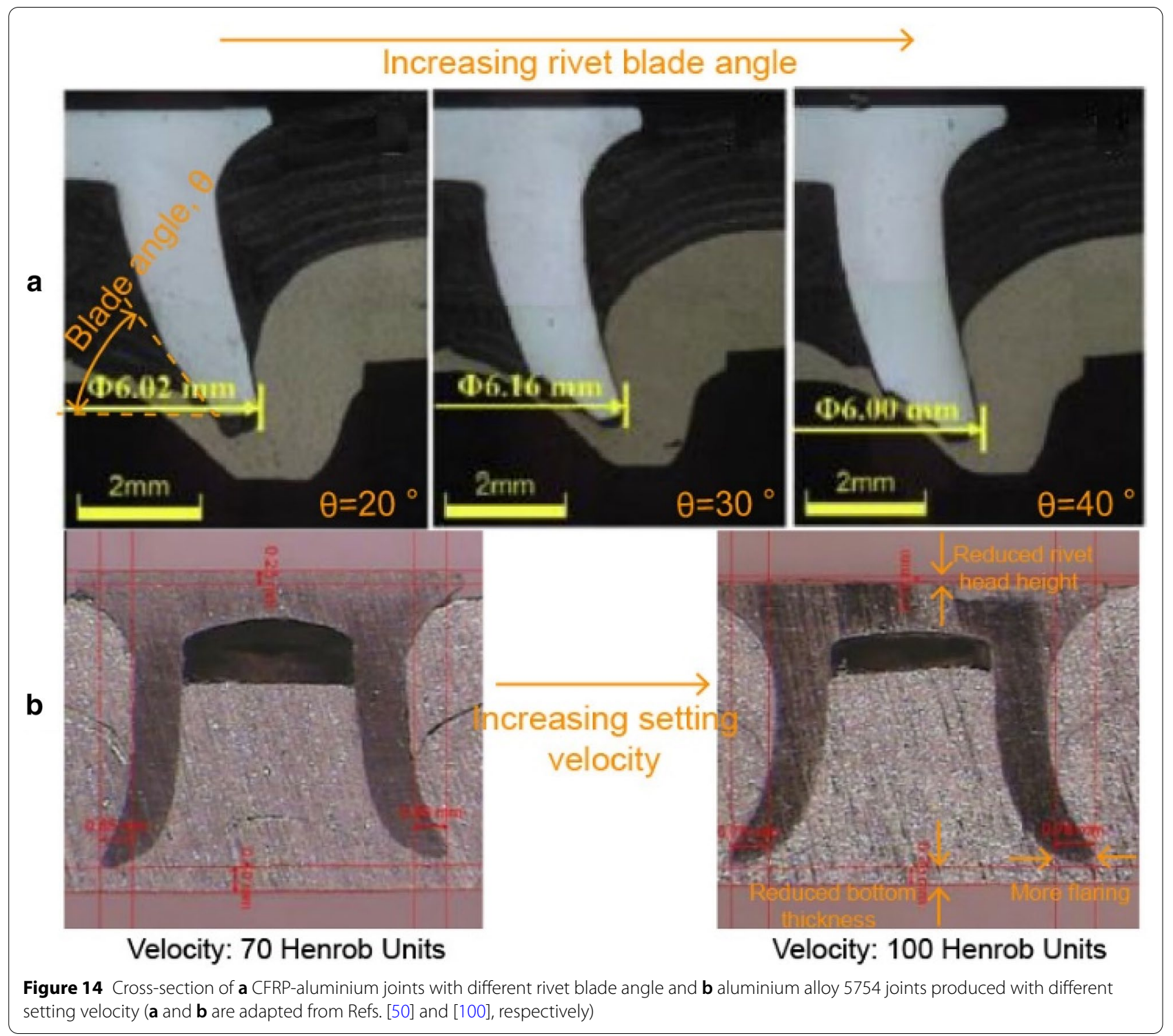

performance of the joints could be further improved if the optimum riveting force was used. Note that, however, increasing the riveting force may increase the residual stress in the rivet and die wear, adversely affecting the tool durability $[9,111]$. Besides, to achieve larger riveting force, SPR equipment is required to have high tonnage and stronger $\mathrm{C}$-frame structure, which in turn may increase the equipment cost.

Alternatively, one can increase the rivet setting velocity instead of the riveting force to improve the interlocking between the rivet and the sheets [100]. The effect of setting velocity is illustrated in Figure 14(b). A higher setting velocity will allow deeper rivet penetration (indicated by the reduced rivet head height and bottom thickness) and larger flaring as observed in Figure 14(b), but note that excessive setting velocity may also result in rivet over-penetrating the lower sheet, leading to corrosion issues [100]. An optimum rivet setting velocity means better joint strength and corrosion resistance.

Optimising the geometry of the die, such as die width, depth, and bottom shape (flat bottom or contoured shape) can improve the die-to-rivet volume ratio to join materials that are harder to join [112]. Pickin et al. [113] made some improvements to rivet flare in joining aluminium by increasing the internal die diameter and reducing the internal die depth. One reason for crack to initiate during SPR process is the presence of tensile stresses at the bottom surface of the lower sheet at the die side, and reducing the internal die depth can help to reduce these stresses. However, reducing the die depth 
might be an issue for certain material combinations such as for joining aluminium sheet with aluminium die castings as a certain amount of die depth is necessary to create a good interlock [62]. Fu and Mallick [114] showed that increasing the die tip height (the distance between the centre tip and die surface) could increase the static strength, but the effect of die tip height on the fatigue life was insignificant. Drossel and Jäckel [62] have also successfully created a new movable die to join high strength aluminium AlSi9Mn die casting which has a limited ductility. With the new movable die, the sheet materials are superimposed with compressive stresses; these compressive stresses are beneficial in counteracting the tensile stresses generated during the riveting process.

Apart from optimisation of die and rivet properties, the thickness of the sheets to be joined is also important. In general, attention should be paid when thicker sheets $(>3$ $\mathrm{mm}$ ) are used as lower sheet, due to difficulties associated with creating a sufficient material interlocking mechanism. The recommended total thickness for materials to be joined are typically up to $6 \mathrm{~mm}$ for steels and 10 $\mathrm{mm}$ for lighter alloys [23]. Ideally, the upper sheet should be at least $0.5 \mathrm{~mm}$ thick and the lower sheet should be at least $1 \mathrm{~mm}$ thick [73]. Theoretically, improvement for riveting thicker materials can be achieved by using larger rivet and die size with a higher riveting force.

Another important parameter is the materials properties of rivet and joining sheets, which have a significant influence on the strength of riveted joints. Materials properties can include yield strength, tensile strength, ductility, strain-rate sensitivity and others, but not all of these properties can influence the riveting ability. A study of SPR literature shows that the influential properties are hardness [109], formability at room temperature $[8,60]$, strain hardening exponent and tensile strength [71, 115]. Material parameters such as plastic strain [116], friction coefficient between the sheets and rivet $[57,70]$ and work hardening behaviour [117] are important factors and they must be accurately defined during SPR numerical simulation to obtain an accurate prediction. Friction between the rivet and sheets does not only influence how rivet deforms, it can also result in plastic strain localisation in the rivet. If the friction is not minimised, it can lead to crack formation in the rivet [70].

SPR involves large and highly localised plastic deformation [45]. During flaring, the rivet forces its way in the lower sheet by displacing materials of the sheets sideways and compressing the materials in the interior of the lower sheet. The lower sheet must have sufficient hardness and strength to resist the lateral displacement so that rivet penetration does not occur while maintaining high strain hardening exponent (n-value) to ensure uniform necking and minimise localised thinning and sheet cracking. At the same time, rivet should not buckle or deform when piercing the upper sheet [115]. Hence, there also exists a limitation to the tensile strength of the upper sheet materials joinable with SPR. In short, sheets must have enough strength, but the strength must be less than that of the rivet. Abe et al. [71] utilised conventional die and rivet (boron steel) to join upper steel sheets of varying tensile strengths with lower aluminium alloy A5052. Increasing the tensile strength of upper steel sheet was observed to increase the interlock between the sheets; maximum interlock achieved at tensile strength of $590 \mathrm{MPa}$, beyond which rivet leg compression occurred. Sheets with high ductility (typically with elongation more than 15\% [76]) also ensure larger spread of rivet leg during flaring, minimising the chances of sheet separation. Commonly, sheet cracking, type of SPR joint defect, is mainly attributed to the low ductility at room temperature $[8,9,60]$, too high tensile strength [71], and too large flow stress of the sheets $[54,71]$.

In terms of rivet properties, hardness, tensile strength and ductility are important properties for a rivet. A rivet must be hard and strong enough to pierce the upper sheet but sufficiently ductile to flare properly in the lower sheet. Rivet with higher strength and ductility than the sheets is recommended [9] so that the sheets would be deformed without obvious upsetting, although this may significantly increase the rivet cost. However, with the strength and hardness improved, ductility is usually compromised as a result of embrittlement. Van Hall et al. [109] employed rivets with different hardness levels for joining upper high strength press-hardened steel to lower heat-treated aluminium alloy 6111. Rivet leg buckling was eliminated when the rivet hardness was increased above $550 \mathrm{HV}$, but radial cracks in rivet leg were observed during flaring into the lower sheet due to low ductility at hardness above $550 \mathrm{HV}$. In short, rivet must be stronger (typical yield strength of $1500 \mathrm{MPa}$ [76]) and harder (typical hardness between 400-530 HV [118]) than the sheets to avoid damage of rivet leg but maintaining good ductility so that rivet leg could spread outwards normally in the lower sheet without being compressed. In order to improve joining performance, both sheets and rivet with improved ductility at high strength levels are required.

\subsection{Advanced SPR Techniques}

As lightweighting becomes the top priority in automotive industry, advanced materials and light alloys, such as high strength steel, aluminium and magnesium alloys, carbon fibre, and polymer composites, are increasingly used to replace cast iron and traditional steel components in transportation vehicles. These advanced light materials have relatively low ductility at room temperature, and often lead to crack formation both inside the joint and on 
the top or bottom surfaces of the joint during SPR process. To effectively rivet these advanced materials, some researchers have made some significant changes to the conventional SPR process [8, 9, 13, 59, 60, 97, 119-122]. These advanced SPR techniques are discussed here, and they are generally more costly than the conventional SPR technique.

Electroplasticity self-piercing riveting (EP-SPR) is an advanced SPR technique proposed by Lou et al. [9] to effectively join advanced high strength steel. High strength steel is a difficult material to rivet due to its large deformation resistance and low formability, resulting in weak interlocking or insufficient penetration with conventional SPR. With EP-SPR, a direct current power supply is first integrated with the SPR equipment, and two pairs of copper brushes are fixed to the high strength steel sheet tightly by bolts to supply electric current to the deforming zone during the riveting process. Applying electric current to the deformation area could improve the plasticity and reduce the deformation resistance of the metal sheet $[123,124]$. EP-SPR joints of aluminium alloy and high strength steel were observed to have less risk of lower sheet penetration, better strength and energy absorption performance as compared to conventional SPR joints [9].

Another hybrid joining method known as rivet welding is proposed by the same authors [97] to join advanced high strength steel with aluminium alloy. The rivet welding process involves two stages, SPR stage and welding stage. A conventional SPR joint is formed first; next an electric current is applied to the riveted sample using two customised annular electrodes to produce resistance heating in the joint during the welding stage. An important parameter in the rivet welding process is the heating time. An optimal heating time can increase the microhardness of the steel rivet and lower steel sheet as well as soften the upper aluminium sheet near the rivet leg, as illustrated in Figures 15(a)-(c). In Figures 15(b)-(d), zero heating time signifies the conventional SPR process, and additional heating in the welding stage is done by either using electrodes A or B. Softening in the aluminium sheet at the regions around the rivet leg allows smoother piercing and spreading of rivet leg, minimising the risk of rivet leg buckling and sheet cracking. Depending on the heating time and the types of electrodes used in the welding stage, rivet welded joints may have higher tensile shear strength than the conventional SPR joints (Figure 15(d)).

Apart from using electric current, another advanced SPR system using gunpowder to push the rivet into the joining aluminium sheets is reported [13]. The gunpowder is first stored in a shell, and when ignited, it impacts on a punch, which hits the rivet head, creating an impact SPR process, which can be completed in less than a millisecond. To avoid excessive deformation of the rivet head and upper sheet, an anvil is placed between the punch and upper sheet to absorb some of the impact forces. Although the joint formed by the impact SPR and a conventional SPR has similar appearance, the amount of plastic deformation in the sheets joined by an impact SPR is significantly reduced due to the high deformation rates. Rivet can pierce the upper sheet without significantly stretching the sheet in a fast riveting process. As a result, there are less tensile stresses created by impact riveting, giving better joint quality and strength than the conventional SPR process.

For joining materials with high hardness and low ductility, such as boron steel [125], stainless steel, aluminium and even thin-walled castings [126], a solid rivet is recommended over the commonly used semi-tubular rivet. This process is known as solid SPR [111, 127, 128]. A solid rivet differs from a semi-tubular rivet because a solid rivet has grooves on its lateral surface. During the process, a solid rivet punches into the sheets and allows the lower sheet material to flow into its circumferential grooves to create a positive interlock. The more grooves are filled by the lower sheet material, the higher joint strength [127]. The difference between solid SPR and conventional SPR is that flaring does not occur in solid SPR, and the solid rivet does not plastically deform in the process [126]. Hence, rivet made of materials with ultrahigh strength and hardness can be utilised, for example to join hard material like boron steel [115] or to join multiple sheets of different thicknesses [126]. However, this may require relatively high process forces for punching the sheet materials and forming an interlock [129]. Solid SPR process enables achieving a flat and relatively smooth surface on one side of the joint, leading to better surface finish [128].

Besides high strength steel and aluminium castings, another difficult material to rivet is magnesium alloys. Due to their hexagonal crystal structure, magnesium alloys have low room-temperature ductility, but their ductility can be improved with increasing temperature due to the activation of additional slip systems at high temperature [130,131]. Therefore, some researchers have modified the conventional SPR process by introducing heating to further improve the ductility and riveting ability of magnesium alloys $[8,59,60,119,132-136]$.

One technique is to combine the joining mechanism of SPR with that of FSSW by making the rivet rotating at high speed during the riveting process. This process is also known as friction self-piercing riveting (F-SPR) by these studies $[8,134-138]$, and it has successfully produced crack-free joints between CFRP and magnesium alloys [134], and between aluminium and magnesium alloys $[8,136]$. Normally, some geometrical features, such 


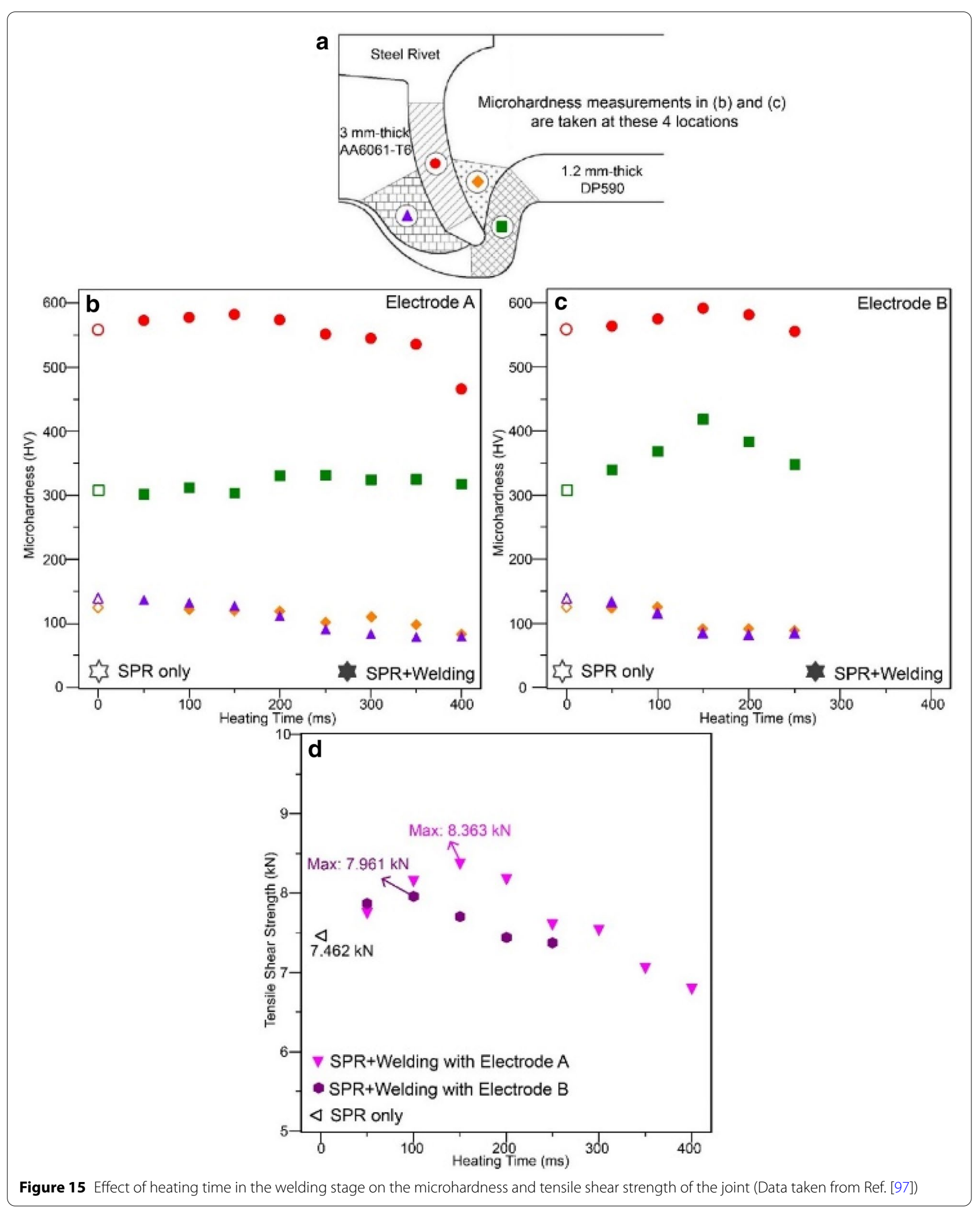


as a torx-shaped or hexagonal-shaped hole, are designed in the rivet head to transmit the rotational motion from a spindle or a drilling machine. During F-SPR, a rivet rotating at high speed will pierce the joining sheets, generating frictional heat between the rivet and sheets. Frictional heat can soften the sheet materials and allow the rivet to pierce into the sheets with less force. When the rivet is fully inserted into the sheets, the rotation stops and punch slowly retracts from the workpiece.

Figure 16 compares an aluminium alloy 6061-magnesium alloy AZ31 joint formed by SPR and F-SPR. In the SPR joint, large cracks were observed in the lower magnesium alloy sheet which propagated to the bottom surface; in the F-SPR joint, no visible cracks were observed when the generated frictional heat was large enough to soften the magnesium alloy sheet [136].

Rivet rotational speed and punch pressure are two important factors in F-SPR. Higher rotational speed generates more frictional heat and reduces the magnitude of sheet cracking, but it can also lead to smaller rivet leg flaring [8]. Higher punch pressure increases the joint interlock, however, excessive punch pressure may fracture the magnesium sheet [132]. F-SPR joints were observed to have superior shear strength [8] and fatigue property when compared with conventional SPR joints $[132,133]$.

Apart from using rivet rotational motion to create heating, other researchers have utilised a laser beam to pre-heat magnesium sheets before riveting; this technique is known as laser-assisted self-piercing riveting (L-SPR) [59, 119]. In L-SPR, prior to riveting, a laser beam will be incident on the surface of the lower magnesium sheet facing the upsetting die to provide noncontact local heating. The laser power and laser dwell

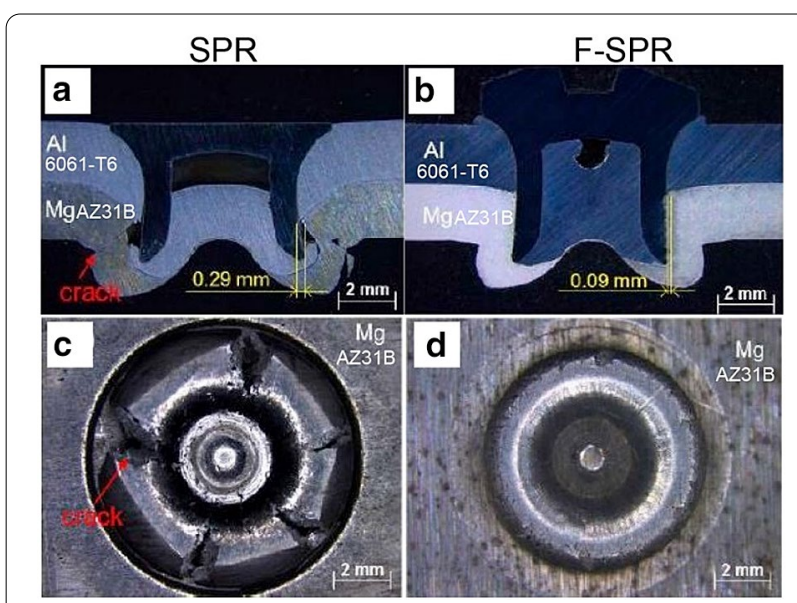

Figure $\mathbf{1 6} \mathbf{a}, \mathbf{b}$ Cross-section and $\mathbf{c}$, $\mathbf{d}$ bottom surface of aluminium-magnesium joints formed by SPR and F-SPR [136] time may be varied depending on the sheets thickness. An infrared thermal imaging camera may also be used to monitor the surface temperature of the laser irradiated area to ensure delivery of right temperature conditions. The laser beam may be used as an add-on machine tool to minimise modification to the existing SPR equipment [59]. L-SPR has effectively joined aluminium and magnesium sheets with a total stack thickness up to 6.6 $\mathrm{mm}$ under $5 \mathrm{~s}$ [119]. With the aid of a laser beam, magnesium sheet cracking can be prevented, and there is also better contact of the rivet head with the surrounding material [119]. Wang et al. [13] proposed a very similar process of pre-heating the magnesium component using an electrical-heated plate rather than a laser beam. Both these studies $[13,59]$ suggested pre-heating magnesium alloy AZ31 to approximately $200{ }^{\circ} \mathrm{C}$ to achieve optimum joint quality. An additional heating process prior to riveting is easy under laboratory settings; however, it may be impractical in the industry as it may require the development of new machine tools. This two-step process also increases process complexity and cost, especially when laser heating is used.

Carbon fibre composites have limited ductility, and damage such as delamination is easily caused during riveting process, affecting the joint performance. To overcome this issue, a novel self-piercing-through riveting (SPTR) was recently proposed [139]. Unlike the conventional SPR, the rivet leg is forced to penetrate through the lower sheet and into contact with the die troughs, and the rivet leg flares out along the trough surfaces to create a hook to lock the upper and lower sheets during SPTR. This process allows more materials to be clinched, creating a stronger mechanical interlock. Therefore, SPTR composite joints were observed to have better static strength than the conventional SPR composite joints [139]. One downside of SPTR is that the protrusion of rivet leg through the lower sheet may affect the aesthetic appearance of the joint.

Adhesive-aided SPR may be a cheaper alternative to join brittle materials, such as magnesium alloys and composites. This process is achieved by combining conventional SPR with adhesive bonding. Typically, adhesive is first spread on the surfaces of the sheet materials to be joined, and then SPR is carried out before hardening of the adhesive. The adhesive-riveted joint is normally cured at room temperature, but it may also subject to post heat-curing treatment [67]. While self-piercing rivet keeps the assembly in position, the adhesive provides additional back-up to prevent joint failure. This hybrid joining technique has been used for magnesium alloys [121], aluminium alloys [140-142] and composite sheets $[66,67]$. Hybrid adhesive-riveted joints were observed to offer higher joint stiffness [67], improved peel and impact 
resistance because crack propagation is arrested by the adhesive bond, and higher static and fatigue strength, although joint strength is also dependent on the type of adhesive used [121]. One challenge in the adhesive-aided SPR is to select a proper adhesive, as adhesive properties may change with temperature. Any thermal stresses or adhesive shrinkage introduced in the joint can adversely affect the joint strength [143].

\section{Conclusions and Future Challenges}

SPR technique has become an increasingly popular mechanical joining method due to the growing use of advanced light materials which are difficult or impossible to weld. In this paper, research and progress of SPR are critically reviewed in different aspects. This paper first provides an overview of the existing problems in SPR process. This includes a discussion of SPR joint failures either resulted from riveting process or due to mechanical loading, and joint corrosion issues. This is then followed by a discussion of the different types of SPR joint optimisation techniques to improve different rivet joints. A major challenge of SPR is its ability to join future generations of lightweight materials as these advanced materials often lack a good combination of high strength and ductility.

Lightweight solutions are a major contribution to the reduction of the impact of vehicles on the environment. The impact of a $100 \mathrm{~kg}$ weight reduction in a vehicle equates to a reduction of $8.7 \mathrm{gCO}_{2} / \mathrm{km}$ emission (derived from [144]). To achieve lightweighting, a key part of the automotive designs of the future is that they will contain mixed material systems in body structures. One of the greatest challenges for SPR is to continue to provide feasible joining solutions to the future generations of lightweight structures which may be a combination of advanced materials, such as composites, high strength steels, aluminium and magnesium alloys. Since SPR involves large and highly localised plastic deformation, riveting materials must have a good combination of high strength and ductility which these advanced materials seem to lack.

SPR often creates damages in composites such as fibre cutting and delamination during piercing and flaring. Low ductility of composites prohibits the rivet leg from spreading, creating more lateral pressure on the composites. Although the material properties of fibre composites may be improved by modifying the fibre orientation and laminate geometry, the properties are still not adequate to resist the large plastic deformation induced by the SPR process. This is because fibre composites are bound by a resin or polymer and punching them by riveting can damage the laminar structures, affecting the composites' strength and stability. These damages may spread and cause premature failure under loading.

High strength and ultra-high strength steels are at least as hard as a typical boron steel rivet if not harder. Since the strength of high strength steel sheet approaches that of the rivet, flaring of rivet leg inside the hard material becomes difficult. As a result, high compressive residual stresses are created in the rivet leg which is often accompanied with a risk of damage in the rivet leg when riveting harder materials.

High strength aluminium alloys are not as problematic as the improved strength is still considerably lower than that of a steel rivet while maintaining a reasonable ductility. However, some series of aluminium alloys, mainly the $2 \mathrm{xxx}, 5 \mathrm{xxx}$, and $7 \mathrm{xxx}$ aluminium alloys are susceptible to stress corrosion cracking. When these aluminium alloys are exposed to corrosive environment and with the presence of internal tensile residual stresses induced by riveting, stress corrosion cracking can initiate and lead to premature failure of SPR joint.

Riveting magnesium alloys to other metals is particularly challenging as cracking of magnesium sheet may occur due to the low formability of magnesium at room temperature. Solution that involves pre-heating the magnesium sheet prior to riveting not only increases the process complexity, time and cost, but also creates an issue on production ability especially when laser heating is used.

Moreover, aluminium and magnesium alloys are often categorised into cast and wrought alloys. Cast alloys account for a relatively large amount of overall use in automotive and aerospace industries as compared to wrought alloys due to the low cost, high level of automation and short processing time in casting. However, castings typically have lower ductility and malleability than wrought alloys due to the non-uniformity of composition and microstructure, and presence of casting defects resulting from non-uniform cooling and uneven solidification rate. The inferior material properties of castings will create another challenge in SPR.

In short, it is apparent that many current advanced lightweight materials do not have adequate material properties to sustain the large plastic deformations induced by the riveting process without failure. Future research should focus on the development of advanced lightweight materials with a good combination of high strength (i.e. yield strength greater than $120 \mathrm{MPa}$ ) and ductility (i.e. elongation greater than 15\%) for SPR.

\section{Acknowledgements}

The author would like to thank Associate Professor Yvonne Durandet from Swinburne University of Technology and Professor Mark Easton from RMIT University for their intellectual discussions on the topic. 


\section{Authors' contributions}

HQA: conceptualisation, investigation, validation, writing, review and editing. The author read and approved the final manuscript.

\section{Authors' information}

Hua Qian Ang is a chartered engineer of Engineers Australia and lecturer at Royal Melbourne Institute of Technology (RMIT) University. Her research areas are focused on the mechanical properties and deformation mechanisms of advanced light alloys, in particular die-cast magnesium alloys. Dr. Ang also has extensive experience in microstructural characterisation in evaluation and improvement of alloys' mechanical properties.

\section{Funding}

Not applicable.

\section{Availability of data and materials}

No datasets presented. Figures previously published elsewhere are reproduced with permission from respective copyright holders/publishers.

\section{Competing interests}

The author declares that he/she has no known competing financial interests or personal relationships that could have appeared to influence the work reported in this paper.

Received: 6 January 2020 Revised: 6 December 2020 Accepted: 9 December 2020

Published online: 04 January 2021

\section{References}

[1] E H Persson. Method of securing a self-piercing and clinching element to a sheet of metal. USPTO, 1971: 3,571,903.

[2] L Han, M Thornton, D Boomer, et al. Effect of aluminium sheet surface conditions on feasibility and quality of resistance spot welding. Journal of Materials Processing Technology, 2010, 210: 1076-1082.

[3] L Deng, Y B Li, W Cai, et al. Simulating thermoelectric effect and its impact on asymmetric weld nugget growth in aluminum resistance spot welding. Journal of Manufacturing Science and Engineering, 2020, 142(9): 091001.

[4] H Litherland. Self-piercing riveting for aluminium applications. Joints in aluminium-INALCO '98: Seventh International Conference Proceedings, Cambridge, UK, 1999: 135.

[5] A Kochan. Audi moves forward with all-aluminium cars. Assembly Automation, 2000, 20(2): 132-135.

[6] J Mortimer. Jaguar uses X350 car to pioneer use of self-piercing rivets. Industrial Robot: An International Journal, 2001, 28(3):192-198.

[7] E Appleton, J Mortimer. Jaguar uses castings, extrusions to reduce parts count in new sports car. Assembly Automation, 2006, 26(2): 115-120.

[8] Y B Li, ZYWei, Z ZWang, et al. Friction self-piercing riveting of aluminum alloy AA6061-T6 to magnesium alloy AZ31B. Journal of Manufacturing Science and Engineering, 2013, 135(6): 061007.

[9] M Lou, Y B Li, Y T Li, et al. Behavior and quality evaluation of electroplastic self-piercing riveting of aluminum alloy and advanced high strength steel. Journal of Manufacturing Science and Engineering, 2013, 135(1): 011005.

[10] B Meyghani, CWu. Progress in thermomechanical analysis of friction stir welding. Chinese Journal of Mechanical Engineering, 2020, 33(12): 1-33.

[11] A Gay, F Lefebvre, S Bergamo, et al. Fatigue performance of a selfpiercing rivet joint between aluminum and glass fiber reinforced thermoplastic composite. International Journal of Fatique, 2016, 83: 127-134.

[12] D Kim, Y Qiu, HY Cho. Design of self-piercing rivet to joint in advanced high strength steel and aluminium alloy sheets. Journal of Welding and Joining, 2015, 33(3): 75-80.

[13] B Wang, C Hao, J Zhang, et al. A new self-piercing riveting process and strength evaluation. Journal of Manufacturing Science and Engineering, 2006, 128(2): 580-587.

[14] M Ishak, L H Shah, I S R Aisha, et al. Study of resistance spot welding between AISI 301 stainless steel and AISI 1020 carbon steel dissimilar alloys. Journal of Mechanical Engineering and Sciences, 2014, 6: 793-806.
[15] Y H Qin, S N Xiao, L T Lu, et al. Structural stress-fatigue life curve improvement of spot welding based on quasi-newton method. Chinese Journal of Mechanical Engineering, 2020, 33: 36.

[16] Z Feng, M L Santella, S A David, et al. Friction stir spot welding of advanced high-strength steels-a feasibility study. SAE Technical Paper, 2005-01-1248: 592-598.

[17] S Aslanlar, A Ogur, U Ozsarac, et al. Welding time effect on mechanical properties of automotive sheets in electrical resistance spot welding. Materials and Design, 2008, 29(7): 1427-1431.

[18] P Briskham, N Blundell, L Han, et al. Comparison of self-pierce riveting, resistance spot welding and spot friction joining for aluminium automotive sheet. SAE Technical Paper, 2006-01-0774.

[19] A Baldan. Adhesively-bonded joints and repairs in metallic alloys, polymers and composite materials: adhesives, adhesion theories and surface pretreatment. Journal of Materials Science, 2004, 39(1): 1-49.

[20] P Mallick. Joining for lightweight vehicles. In: Materials, Design and Manufacturing for Lightweight Vehicles. P Mallick (Ed). Woodhead Publishing, 2020: Chapter 8, 275-308.

[21] X Zhu, Y B Li, J Ni, et al. Curing-induced debonding and its influence on strength of adhesively bonded joints of dissimilar materials. Journal of Manufacturing Science and Engineering, 2016, 138(6): 061005.

[22] X Zhu, Y B Li, G L Chen, et al. Curing-induced distortion mechanism in adhesive bonding of aluminum AA6061-T6 and steels. Journal of Manufacturing Science and Engineering, 2013, 135(5): 051007.

[23] X He, I Pearson, K Young. Self-pierce riveting for sheet materials: state of the art. Journal of Materials Processing Technology, 2008, 199(1): 27-36.

[24] D Li, A Chrysanthou, I Patel, et al. Self-piercing riveting-a review. The International Journal of Advanced Manufacturing Technology, 2017, 92: 1777-1824.

[25] K Mori, Y Abe, T Kato. Mechanism of superiority of fatigue strength for aluminium alloy sheets joined by mechanical clinching and selfpierce riveting. Journal of Materials Processing Technology, 2012, 212(9): 1900-1905.

[26] X Sun, E V Stephens, M A Khaleel. Fatigue behaviors of self-piercing rivets joining similar and dissimilar sheet metals. International Journal of Fatigue, 2007, 29(2): 370-386.

[27] H Mizukoshi, H Okada. Fatigue properties of mechanical fastening joints. Materials Science Forum, 1997, 242: 231-238.

[28] X Sun, EV Stephens, M A Khaleel, et al. Resistance spot welding of aluminum alloy to steel with transition material-from process to performance-Part I: Experimental study. Welding Journal New York, 2004 83: 188-195.

[29] G S Booth, C A Olivier, S A Westgate, et al. Self-piercing riveted joints and resistance spot welded joints in steel and aluminium. SAE Technical Paper, 2000-01-2681.

[30] G Razmjoo, S A Westgate. Fatigue properties of clinched, self-piercing riveted and spot welded joints in steel and aluminium alloy sheet. TWI Report, 1999, https://www.twi-global.com/.

[31] K Miller, Y Chao, P Wang. Performance comparison of spot-welded, adhesive bonded, and self-piercing riveted aluminium joints. ASM Proceedings of the International Conference: Trends in Welding Research, Georgia, USA, June 1-5, 1998: 910-915.

[32] A Krause, R Chernenkoff. A comparative study of the fatique behavior of spot welded and mechanically fastened aluminum joints. SAE Technical Paper, 1995: 950710.

[33] K Mori, Y Abe, T Kato. Self-pierce riveting of multiple steel and aluminium alloy sheets. Journal of Materials Processing Technology, 2014, 214(10): 2002-2008.

[34] X He, Y Wang, Y Lu, et al. Self-piercing riveting of similar and dissimilar titanium sheet materials. The International Journal of Advanced Manufacturing Technology, 2015, 80: 2105-2115.

[35] K Mori, T Kato, Y Abe, et al. Plastic joining of ultra high strength steel and aluminium alloy sheets by self piercing rivet. CIRP Annals, 2006, 55(1): 283-286.

[36] E Atzeni, R Ippolito, L Settineri. Experimental and numerical appraisal of self-piercing riveting. CIRP Annals-Manufacturing Technology, 2009, 58(1): 17-20.

[37] R Haque, N S Williams, S E Blacket, et al. A simple but effective model for characterizing SPR joints in steel sheet. Journal of Materials Processing Technology, 2015, 223: 225-231. 
[38] R Haque, J Beynon, Y Durandet. Characterisation of force-displacement curve in self-pierce riveting. Science and Technology of Welding and Joining, 2012, 17(6): 476-488.

[39] B Xing, X He, Y Wang, et al. Study of mechanical properties for copper alloy $\mathrm{H} 62$ sheets joined by self-piercing riveting and clinching. Journal of Materials Processing Technology, 2015, 216: 28-36.

[40] R Cacko. Review of different material separation criteria in numerical modeling of the self-piercing riveting process-SPR. Archives of Civil and Mechanical Engineering, 2008, 8(2): 21-30.

[41] P Johnson. Quality control and non-destructive testing of self-piercing riveted joints in aerospace and other applications. In: Welding and Joining of Aerospace Materials. M C Chaturvedi (Ed.). Woodhead Publishing, 2012: 215-234.

[42] L Han, R Hewitt, M Shergold, et al. An evaluation of NDT for self-pierce riveting. SAE Technical Paper, 2007-01-1364.

[43] W Cai, P Wang, W Yang. Assembly dimensional prediction for selfpiercing riveted aluminum panels. International Journal of Machine Tools and Manufacture, 2005, 45(6): 695-704.

[44] R Cacko, P Czyżewski. Verification of numerical modelling of the SPR joint by experimental stack-up. Computer Methods in Materials Science, 2007, 7(1): 124-130.

[45] R Porcaro, A G Hanssen, M Langseth, et al. Self-piercing riveting process: An experimental and numerical investigation. Journal of Materials Processing Technology, 2006, 171(1): 10-20.

[46] P Johnson, J D Cullen, A I Al-Shamma'a, et al. Online visual inspection of self-piercing riveting to determine the quality of the mechanical interlock. Journal of Physics: Conference Series, 2007, 76(1): 012012.

[47] R Haque. Quality of self-piercing riveting (SPR) joints from cross-sectional perspective: A review. Archives of Civil and Mechanical Engineering, 2018, 18(1): 83-93.

[48] L Han, A Chrysanthou. Evaluation of quality and behaviour of selfpiercing riveted aluminium to high strength low alloy sheets with different surface coatings. Materials and Design, 2008, 29(2): 458-468

[49] YXu. Effects of factors on physical attributes of self-piercing riveted joints. Science and Technology of Welding and Joining, 2006, 11(6): 666-671.

[50] H Jiang, S Gao, G Li, et al. Structural design of half hollow rivet for electromagnetic self-piercing riveting process of dissimilar materials. Materials and Design, 2019, 183: 108141.

[51] L Han, M Thornton, D Li, et al. Effect of setting velocity on self-piercing riveting process and joint behaviour for automotive applications. SAE Technical Paper, 2010-01-0966.

[52] TStepinski. Assessing quality of self-piercing rivets using ultrasound. 9th European Conference on Non-Destructive Testing, Berlin, Germany, September 25-29, 2006.

[53] TStepinski, M Engholm. Narrowband ultrasonic spectroscopy for inspecting multilayered aerospace structures. 9th European Conference on Non-Destructive Testing, Berlin, Germany, September 25-29, 2006.

[54] Y Abe, T Kato, K Mori. Joinability of aluminium alloy and mild steel sheets by self piercing rivet. Journal of Materials Processing Technology, 2006, 177(1): 417-421.

[55] J Zhang, S Yang. Self-piercing riveting of aluminum alloy and thermoplastic composites. Journal of Composite Materials, 2015, 49(12): 1493-1502.

[56] K Mori, Y Abe. A review on mechanical joining of aluminium and high strength steel sheets by plastic deformation. International Journal of Lightweight Materials and Manufacture, 2018, 1(1): 1-11.

[57] D Li. Influence of aluminium sheet surface modification on the selfpiercing riveting process and the joint static lap shear strength. The International Journal of Advanced Manufacturing Technology, 2017, 93(58): $2685-2695$

[58] A Chrysanthou, X Sun. Self-piercing riveting: properties, processes and applications. Woodhead Publishing, 2014.

[59] Y Durandet, R Deam, A Beer, et al. Laser assisted self-pierce riveting of AZ31 magnesium alloy strips. Materials and Design, 2010, 31: S13-S16.

[60] JW Wang, Z X Liu, Y Shang, et al. Self-piercing riveting of wrought magnesium AZ31 sheets. Journal of Manufacturing Science and Engineering, 2011, 133(3): 031009.

[61] A Luo, T Lee, J Carter. Self-pierce riveting of magnesium to aluminum alloys. SAE International of Journal of Materials and Manufacturing, 2011, 4: 158-165.
[62] W G Drossel, M Jäckel. New die concept for self-pierce riveting materials with limited ductility. Key Engineering Materials, 2014, 611-612: 1452-1459.

[63] L Fratini, V F Ruisi. Self-piercing riveting for aluminium alloys-composites hybrid joints. International Journal of Advanced Manufacturing Technology, 2009, 43(1-2): 61-66.

[64] G Di Franco, L Fratini, A Pasta, et al. On the self-piercing riveting of aluminium blanks and carbon fibre composite panels. International Journal of Material Forming, 2013, 6(1): 137-144.

[65] M Jäckel, T Grimm, R Niegsch, et al. Overview of current challenges in self-pierce riveting of lightweight materials. Multidisciplinary Digital Publishing Institute Proceedings, Brussels, Belgium, July 1-5, 2018, 2(8): 384-389.

[66] G Di Franco, L Fratini, A Pasta. Influence of the distance between rivets in self-piercing riveting bonded joints made of carbon fiber panels and AA2024 blanks. Materials and Design, 2012, 35: 342-349.

[67] G Di Franco, L Fratini, A Pasta. Analysis of the mechanical performance of hybrid (SPR/bonded) single-lap joints between CFRP panels and aluminum blanks. International Journal of Adhesion and Adhesives, 2013, 41: 24-32.

[68] H M Rao, J Kang, G Huff, et al. Impact of specimen configuration on fatigue properties of self-piercing riveted aluminum to carbon fiber reinforced polymer composite. International Journal of Fatigue, 2018, 113: 11-22.

[69] N H Hoang, R Porcaro, M Langseth, et al. Self-piercing riveting connections using aluminium rivets. International Journal of Solids and Structures, 2010, 47(3): 427-439.

[70] N H Hoang, O S Hopperstad, M Langseth, et al. Failure of aluminium self-piercing rivets: An experimental and numerical study. Materials and Design, 2013, 49: 323-335.

[71] Y Abe, T Kato, K Mori. Self-piercing riveting of high tensile strength steel and aluminium alloy sheets using conventional rivet and die. Journal of Materials Processing Technology, 2009, 209(8): 3914-3922.

[72] J Eckstein, E Roos, K Roll, et al. Experimental and numerical investigations to extend the process limits in self-pierce riveting. AIP Conference Proceedings, Spain, April 18-20, 2007, 907(1): 279-286.

[73] J Sprovieri. Advances in self-piercing riveting. Assembly, 2018, 61(9): 42-45.

[74] X Sun, M A Khaleel. Dynamic strength evaluations for self-piercing rivets and resistance spot welds joining similar and dissimilar metals. International Journal of Impact Engineering, 2007, 34(10): 1668-1682.

[75] L Calabrese, E Proverbio, G Di Bella, et al. Failure behaviour of SPR joints after salt spray test. Engineering Structures, 2015, 82: 33-43.

[76] X Sun, M A Khaleel. Performance optimization of self-piercing rivets through analytical rivet strength estimation. Journal of Manufacturing Processes, 2005, 7(1): 83-93.

[77] R Porcaro, A G Hanssen, M Langseth, et al. The behaviour of a selfpiercing riveted connection under quasi-static loading conditions. International Journal of Solids and Structures, 2006, 43(17): 5110-5131.

[78] R Porcaro, A G Hanssen, M Langseth, et al. An experimental investigation on the behaviour of self-piercing riveted connections in aluminium alloy AA6060. International Journal of Crashworthiness, 2010, 11(5): 397-417.

[79] Z M Su, P C Lin, W J Lai, et al. Fatigue analyses of self-piercing rivets and clinch joints in lap-shear specimens of aluminum sheets. International Journal of Fatigue, 2015, 72: 53-65.

[80] Y Lu, X C He, Y F Wang. Study on mechanical properties of self-piercing riveted joints about titanium alloy. Applied Mechanics and Materials, 2015, 723: 856-859.

[81] S H Kang, H K Kim. Fatigue strength evaluation of self-piercing riveted Al-5052 joints under different specimen configurations. International Journal of Fatique, 2015, 80: 58-68.

[82] B Xing, X He, K Zeng, et al. Mechanical properties of self-piercing riveted joints in aluminum alloy 5052. International Journal of Advanced Manufacturing Technology, 2014, 75(1-4): 351-361.

[83] L Han, A Chrysanthou, KW Young. Mechanical behaviour of self-piercing riveted multi-layer joints under different specimen configurations. Materials and Design, 2007, 28(7): 2024-2033.

[84] X Sun, M A Khaleel. Strength estimation of self-piercing rivets using lower bound limit load analysis. Science Technology of Welding Joining, 2005, 10(5): 624-635. 
[85] D Li, L Han, M Thornton, et al. The influence of fatigue on the stiffness and remaining static strength of self-piercing riveted aluminium joints. Materials and Design, 2014, 54: 301-314.

[86] Y K Chen, L Han, A Chrysanthou, et al. Fretting wear in self-piercing riveted aluminium alloy sheet. Wear, 2003, 255(7): 1463-1470.

[87] X He, L Zhao, C Deng, et al. Self-piercing riveting of similar and dissimilar metal sheets of aluminum alloy and copper alloy. Materials and Design, 2015, 65: 923-933.

[88] L Huang, J Bonnen, J Lasecki, et al. Fatique and fretting of mixed metal self-piercing riveted joint. International Journal of Fatigue, 2014, 83 230-239.

[89] M Szolwinski, T Farris. Linking riveting process parameters to the fatigue performance of riveted aircraft structures. Journal of Aircraft, 2000, 37(1): 130-137.

[90] X Zhang, X He, F Gu, et al. Self-piercing riveting of aluminium-lithium alloy sheet materials. Journal of Materials Processing Technology, 2019, 268: 192-200.

[91] X Zhang, X He, W Wei, et al. Fatigue characterization and crack propagation mechanism of self-piercing riveted joints in titanium plates. International Journal of Fatigue, 2020, 134: 105465.

[92] L Han, A Chrysanthou, J O'Sullivan. Fretting behaviour of self-piercing riveted aluminium alloy joints under different interfacial conditions. Materials and Design, 2006, 27(3): 200-208.

[93] K lyer, F L Brittman, S J Hu, et al. Fatigue and fretting of self-piercing riveted joints. ASME 2002 International Mechanical Engineering Congress and Exposition, Louisiana, USA, November 17-22, 2002: 401-415.

[94] L Zhao, X He, B Xing, et al. Influence of sheet thickness on fatigue behavior and fretting of self-piercing riveted joints in aluminum alloy 5052. Materials and Design, 2015, 87: 1010-1017.

[95] L Calabrese, E Proverbio, G Di Bella, et al. Assessment of ageing effect on the mechanical behaviour of steel/aluminium self-piercing riveted joint. International Journal of Mechanical and Materials Engineering, 2015, 10(1): 1-13.

[96] X He, F Gu, A Ball. Recent development in finite element analysis of selfpiercing riveted joints. International Journal of Advanced Manufacturing Technology, 2012, 58(5-8): 643-649.

[97] M Lou, Y B Li, Y Wang, et al. Influence of resistance heating on selfpiercing riveted dissimilar joints of AA6061-T6 and galvanized DP590. Journal of Materials Processing Technology, 2014, 214(10): 2119-2126.

[98] M A Karim, J H Bae, D H Kam, et al. Assessment of rivet coating corrosion effect on strength degradation of CFRP/aluminum self-piercing riveted joints. Surface and Coatings Technology, 2020, 393: 125726.

[99] R Howard, S Sunday. The corrosion performance of steel self-piercing rivets when used with aluminum components. SAE Technical Paper, 1983: 831816.

[100] D Li, L Han, A Chrysanthou, et al. The effect of setting velocity on the static and fatigue strengths of self-piercing riveted joints for automotive applications. TMS 2014: $143^{\text {rd }}$ Annual Meeting \& Exhibition, California, USA, February 16-20, 2014: 557-564.

[101] J loannou. Mechanical behaviour and corrosion of interstitial-free steelaluminium alloy self-piercing riveted joints. UK: University of Hertfordshire, 2010

[102] S Hiromoto. Corrosion of metallic biomaterials. In: Metals for biomedical devices. M Niinomi (Ed.). Woodhead publishing, 2019: Chapter 4.

[103] G L Song, A Atrens. Corrosion mechanisms of magnesium alloys. Advanced Engineering Materials, 1999, 1(1): 11-33.

[104] G Makar, J Kruger. Corrosion of magnesium. International Materials Reviews, 1993, 38(3): 138-153.

[105] A S H Makhlouf. Intelligent stannate-based coatings of self-healing functionality for magnesium alloys. In: Intelligent Coatings for Corrosion Control. A Tiwari, J Rawlins, L Hihara (Eds.). Elsevier, 2015: Chapter 15, 537-555.

[106] L Calabrese, E Proverbio, E Pollicino, et al. Effect of galvanic corrosion on durability of aluminium/steel self-piercing rivet joints. Corrosion Engineering, Science and Technology, 2015, 50(1): 10-17.

[107] M Jäckel, T Grimm, D Landgrebe. Approaches for mechanical joining of $7 \mathrm{xxx}$ series aluminum alloys. AIP Conference Proceedings, France, April 27-29, 2016, 1769(1): 100010.

[108] L Calabrese, L Bonaccorsi, E Proverbio, et al. Durability on alternate immersion test of self-piercing riveting aluminium joint. Materials \& Design, 2013, 46: 849-856.
[109] S Van Hall, K Findley, A Campbell. Evaluating the performance of current self-pierce rivet technology for the joining of high strength steel and aluminum alloys. ASME 2014 International Manufacturing Science and Engineering Conference collocated with the JSME 2014 International Conference on Materials and Processing and the 42nd North American Manufacturing Research Conference, Michigan, USA, July 9-13, 2014.

[110] E Sjöström, J Gårdstam, RTrinick. Development of martensitic stainless steel rivets for applications of self piercing riveting of stainless steel sheets. Swedish Institute for Metals Research, 2004

[111] J Mucha. The numerical analysis of the effect of the joining process parameters on self-piercing riveting using the solid rivet. Archives of Civil and Mechanical Engineering, 2014, 14(3): 444-454.

[112] YW Ma, M Lou, Y B Li, et al. Effect of rivet and die on self-piercing rivetability of AA6061-T6 and mild steel CR4 of different gauges. Journal of Materials Processing Technology, 2018, 251:282-294.

[113] C Pickin, K Young, I Tuersley. Joining of lightweight sandwich sheets to aluminium using self-pierce riveting. Materials and Deign, 2007, 28(8): 2361-2365.

[114] M Fu, P Mallick. Effect of process variables on the static and fatigue properties of self-piercing riveted joints in aluminum alloy 5754. SAE Technical Paper, 2001-01-0825.

[115] G Meschut, V Janzen, T Olfermann. Innovative and highly productive joining technologies for multi-material lightweight car body structures. Journal of Materials Engineering and Performance, 2014, 23(5): 1515-1523.

[116] G Casalino, A Rotondo, A Ludovico. On the numerical modelling of the multiphysics self piercing riveting process based on the finite element technique. Advances in Engineering Software, 2008, 39(9): 787-795.

[117] P Bouchard, T Laurent, L Tollier. Numerical modeling of self-pierce riveting - from riveting process modeling down to structural analysis. Journal of Materials Processing Technology, 2008, 202(1): 290-300.

[118] K Mori, N Bay, L Fratini, et al. Joining by plastic deformation. CIRP AnnalsManufacturing Technology, 2013, 62(2): 673-694.

[119] M Easton, A Beer, M Barnett, et al. Magnesium alloy applications in automotive structures. JOM, 2008, 60(11): 57-62.

[120] L France, R Freeman. Welding and joining of magnesium. SAE Technical Paper, 2001-01-3443.

[121] Y Miyashita, Y C J Teow, T Karasawa, et al. Strength of adhesive aided SPR joint for AM50 magnesium alloy sheets. Procedia Engineering, 2011, 10: $2532-2537$.

[122] L Deng, M Lou, $Y$ Li, et al. Thermally assisted self-piercing riveting of AA6061-T6 to ultra high strength steel. Journal of Manufacturing Science, 2019, 141(10): 101006

[123] H Conrad. Electroplasticity in metals and ceramics. Materials Science Engineering A, 2000, 287(2): 276-287.

[124] H Conrad. Thermally activated plastic flow of metals and ceramics with an electric field or current. Materials Science Engineering A, 2002, 322(12): 100-107.

[125] O Hahn, G Meschut, M Bergau, et al. Self-pierce riveting and hybrid joining of boron steels in multi-material and multi-sheet joints. Procedia CIRP, 2014, 18: 192-196.

[126] J Mucha, E Spisak, L Koscak. Non-standard car body element joining process with solid self-piercing rivet. Archiwum Motoryzacji, 2011, 2: 57-67.

[127] J Mucha. The failure mechanics analysis of the solid self-piercing riveting joints. Engineering Failure Analysis, 2015, 47: 77-88.

[128] J Mucha. The effect of material properties and joining process parameters on behavior of self-pierce riveting joints made with the solid rivet. Materials and Design, 2013, 52: 932-946.

[129] G Meschut, M Matzke, R Hoerhold, et al. Hybrid technologies for joining ultra-high-strength boron steels with aluminum alloys for lightweight car body structures. Procedia CIRP, 2014, 23: 19-23.

[130] H Q Ang. Mechanical properties and deformation behaviour of highpressure die-cast magnesium-aluminium based alloys. Australia: RMIT University, 2017.

[131] H Q Ang, T Abbott, S M Zhu, et al. An analysis of the tensile deformation behavior of commercial die-cast magnesium-aluminum-based alloys. Metallurgical and Materials Transactions A, 2019, 50(8): 3827-3841.

[132] H Duan, G Han, M Wang, et al. Rotation friction pressing riveting of AZ31 magnesium alloy sheet. Materials and Design, 2014, 54: 414-424. 
[133] G Han, M Wang, Z Liu, et al. A new joining process for magnesium alloys: rotation friction drilling riveting. Journal of Manufacturing Science and Engineering, 2013, 135(3): 031012.

[134] Y C Lim, C D Warren, J Chen, et al. Joining of lightweight dissimilar materials by friction self-piercing riveting. In: Friction stir welding and processing X. Y Hovanski, R Mishra, Y Sato, et al. (Eds.). Springer, 2019: 189-195.

[135] X Liu, Y C Lim, Y Li, et al. Effects of process parameters on friction selfpiercing riveting of dissimilar materials. Journal of Materials Processing Technology, 2016, 237: 19-30.

[136] Y Ma, X Xian, M Lou, et al. Friction self-piercing riveting (F-SPR) of dissimilar materials. Procedia Engineering, 2017, 207: 950-955.

[137] Y Ma, B Yang, M Lou, et al. Effect of mechanical and solid-state joining characteristics on tensile-shear performance of friction self-piercing riveted aluminum alloy AA7075-T6 joints. Journal of Materials Processing Technology, 2020, 278: 116543.

[138] XXian, Y Ma, H Shan, et al. Single-sided joining of aluminum alloys using friction self-piercing riveting (F-SPR) process. Journal of Manufacturing Processes, 2019, 38: 319-327.
[139] Z Rao, L Ou, Y Wang, et al. A self-piercing-through riveting method for joining of discontinuous carbon fiber reinforced nylon 6 composite. Composite Structures, 2020, 237: 111841.

[140] F Moroni, A Pirondi, F Kleiner. Experimental analysis and comparison of the strength of simple and hybrid structural joints. International Journal of Adhesion and Adhesives, 2010, 30(5): 367-379.

[141] F Moroni. Fatigue behaviour of hybrid clinch-bonded and self-piercing rivet bonded joints. The Journal of Adhesion, 2019, 95(5-7): 577-594.

[142] L Potgorschek, J Domitner, F Hönsch, et al. Numerical simulation of hybrid joining processes: self-piercing riveting combined with adhesive bonding. Procedia Manufacturing, 2020, 47: 413-418.

[143] L Da Silva. Improving bonding at high and low temperatures. In: Advances in structural adhesive bonding. D A Dillard (Ed.). Woodhead Publishing, 2010: 516-546.

[144] M Espig, M Johannaber, R Wohlecker. Simulation der verbrauchsverbesserung durch gewichtsreduzierung. In Pkw. ATZ-Automobiltechnische Zeitschrift. Springer, 2006, 108(12): 1086-1090.

\section{Submit your manuscript to a SpringerOpen ${ }^{\circ}$ journal and benefit from:}

- Convenient online submission

- Rigorous peer review

- Open access: articles freely available online

- High visibility within the field

- Retaining the copyright to your article

Submit your next manuscript at $\gg$ springeropen.com 